thod to facilitate yarn-guiding. Yarn is nipped securely between the aprons of the top and bottom rollers forfeeding.

The cooling part, being $300 \mathrm{~mm}$ long and placed under the heater, gives a reasonable cooling effect. The heater temperature is controlled for every spindle. There is a continuous temperature-watching device which can be connected by a connector to each spindle. This is somewhat cheaper than a built-in temperature indicator.

The price is about $\$ 220$ per spindle. This is a low price for a 400,000 rpm, $1,000 \mathrm{~mm}$ heater. The winding package is $2 \mathrm{Kgs}$. Steps are presently being taken to increase packages for feeding from 2 to $3 \mathrm{lbs}$. The package-winding capacity, then, has to be upped to $6 \mathrm{lbs}$. to please users.

Main specifications :

Number of spindles $\quad 160$

Packages for winding 2 Kgs. each

Revolution speed of spindle 110,000-4000,000

$\mathrm{rpm}$

Yarn speed

Heater length

$40-120 \mathrm{~m} / \mathrm{min}$

$1,000 \mathrm{~mm}$ (effective length $960 \mathrm{~mm})$

Range of heater temperature control $100-250^{\circ} \mathrm{C}$

Accuracy of heater temperature control $\pm 1^{\circ} \mathrm{C}$

Build of heater heating by 1 resistance wire per 2 spindles

System of heater control, By SCR, spindles by spindle

Frame length $\quad 12,585 \mathrm{~mm}$

Frame width (excluding operation stand)

Frame height

$2,952 \mathrm{~mm}$

$1,312 \mathrm{~mm}$

\section{Conversion of Yarns into} Fabrics

\section{Preparatory machines for weaving or knitting}

\section{(Automatic winder)}

Many continuous automatic spinning systems have been marketed in our country, and some of them have been used, with good results, in three-shift operations in mills. They seem to foretell the achievement of complete, unmanned automation before long. However, no drastic improvements have yet been made in the winding system because in some cases, cheeses have to be sold packed in various shapes. The immediate problem, therefore, is how to modernize the winding process which, at present, takes many operators. Autowinders are looked upon as a solution.

Auto-winder exhibits at the fair included-Kamitsu's Kamimat Auto Winder and MT Auto Winder, Shimadzu's SA type Full Auto winder and Murata's No. 10AW Automatic Cone Winder. Each was a definite effort at complete automation and mechanical stability which the textile industry seeks.

Kamimat worked well. Murata's and Shimadzu's auto winders were equipped with an automatic supply cop feeder, an automatic doffer and a knotter(re-knotter) of end breakage with a target knotting speed of 35 knots per minute.

Their productivity was distinctly high. Yet, they were behind the world's top-level auto-winders in highspeed winding and treatment of high-quality yarns. Murata's Gilbos and Ishikawa's Abbott winders-nearing completion-which are designed to wind yarns hav. ing high breakage rates and to wind them in small quantities, were not exhibited.

\section{(1) Kamimat Auto Winder}

Kamitsu Seisakusho Ltd.

This winder has an automatic knotter which reknots broken yarn-ends on every spindle; an automatic yarn-end loosener and an automatic cop distributor. It can wind at a speed as high as $1,000 \mathrm{~m} / \mathrm{min}$.

This winder was displayed in Japan for the third time. It had been favorably noticed by expert mill men from all over the world at the last Atlantic City Exhibition. We omit a detailed description of this winder here, because it differs little in appearance from the one exhibited at the 1965 Tokyo International Trade Fair and its mechanism has been illustrated in previous issues of this journal.

No strikingly new ideas have been introduced into this winder since last year, but a series of renovations have been made for better and more stabilized working. We can safely say that it is a perfect service auto.

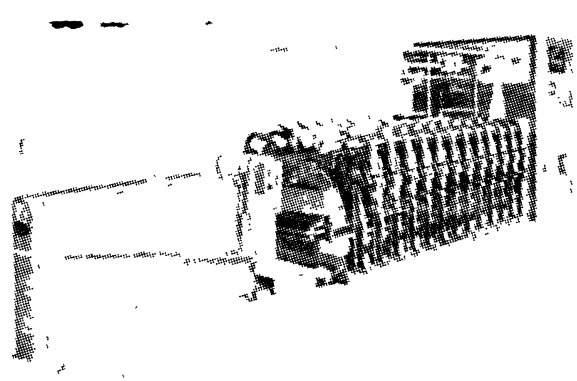

Fig. 1 Kamimat Auto Winder 
winder within the limits of its specifications. Latest major improvements are increased efficiency in the taking up of yarn ends during package-winding and cone-supplying, an auto-counter for supply cops, and a better shape of wound packages.

Further improvements desired are provision for

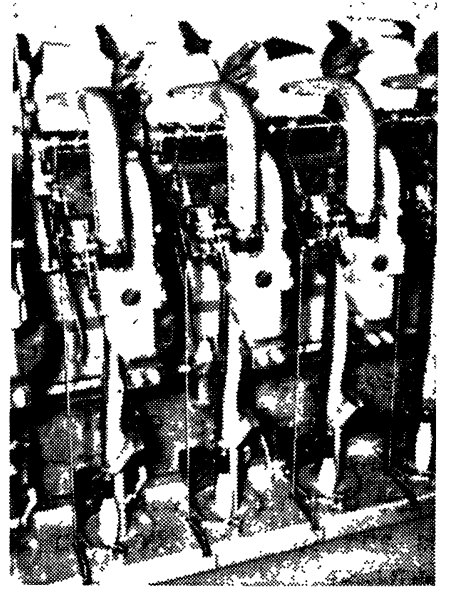

Fig. 2 Kamimat

Auto

winder

treatment of high-quality yarns (e.g., finer yarns, syn. thetic and chemical fibers, and waxing, an 'electronic slub catcher and a weavers' knotter) and higher efficiency (e.g., automatic doffing, automatic picking out of irregular cops, and small-lot operation).

This winder as it now is unquestionably ranks first in Japan. With the further improvements added, it will be among the world's best winders in efficiency and economic advantages.

\section{(2) Automatic Winder SA Type}

\section{Shimadzu Seisakusho Ltd.}

This winder has a travelling winding unit for large and medium lots, an automatic cop-feeder, auto. matic re-knotter and automatic doffer. It can be equipped with two types of doffers, the simultaneous type and the random system with an auto-counter which works by a predetermined number of full cops. Its operation rate goal:30 knots per minute at a yarn speed of 1,000 meters per minute.

While cops piled up in the hopper-bin of the auto. feeder are moving on the lattice, their yarn ends are picked up and sent into the knotter part. Irregular cops are automatically picked out and ejected out of the feeder during supply.. Yarn-breakage during winding is perceived by a bypass system and the broken yarn is automatically tied by the re-knotter. The re-knotter, like Murata's No.10A-W, was displayed for the first time at this fair. It removes the broken yarn ends of cops out

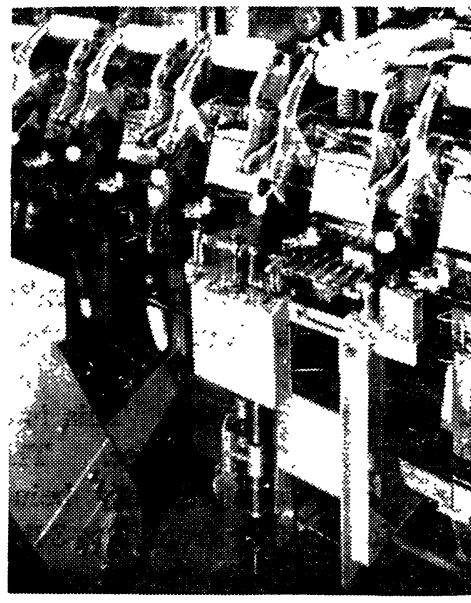

Fig. 3 SAW bypass device and automatic counter

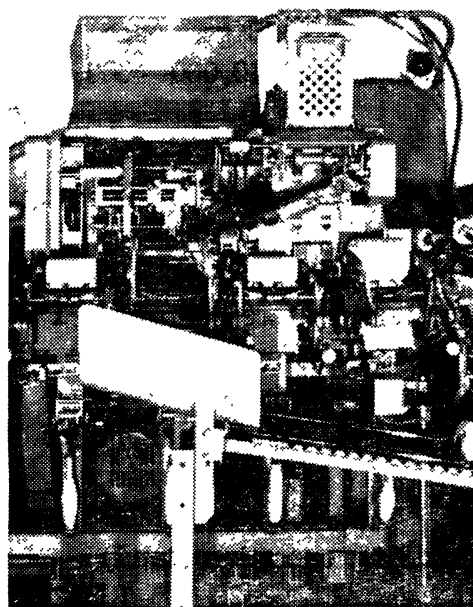

Fig. 4 SAW auto doffer

of the tension parts and supplies them again to the knotter. The re-knotter can be placed on the supply magazine head of the machine $\left(\mathrm{MK}_{1}\right)$ or in the middle $\left(\mathrm{MK}_{2}\right)$.

After a wound cheese is kontted, its fag-end is wound on its core for doffing by the auto-doffer. The end of winding yarn is wound on a new cheese bobbin and is put on the cradle. Then the next winding begins automatically. In case of random doffing, the counter of each winding unit indicates a full package and directs the auto-doffer to go into operation.

The combination of the auto-feeder, auto-doffer, auto-reknotter bypass device, auto-counter, empty bob. bin disposer, etc. makes it possible for one operator to mind several machines. He has only to watch for and correct misoperation. Like every other travelling winder, this machine is apt to suffer from repeated misoperations, which can often deteriorate yarn quality.

Therefore, this winder has safety devices, such as 
a double-yarn preventive cutter, misknot cutter, etc. It has also an automatic stopper for the travelling unit.

The winder has, as a specail device for simultaneous doffing, an automatic stopper which stops the travelling units if a cop is not unwound, and completes untwinding to start the unit again.

\section{(3) Murata's No. 10 Fully Automatic Cone/ Cheese Winder}

\section{Murata Machinery, Ltd.}

Murata Machinery Co., Ltd. manufactures Fully Automatic Cone/Cheese Winder No. 66-AW (Abbott) and No. 11 cone matic (Gilbos), a new line for them, under technical tie-ups. No. $10-\mathrm{AW}$ is a unit travelling automatic winder developed entirely on Murata's own resources with conditions peculiar to Japanese mills taken into consideration.

No. 10-AW with ACF (Automatic Cop Feeder) and an automatic re-knotter attached, had been shown at previous Osaka International Trade Fair. It has been sold to many mills and is familiar to all. New major devices attached to the exhibit at the last fair included a new type of ACF (ACF-D type) and a cheese autodoffer. Various other improvements in minute parts were noticed. No. $10-\mathrm{AW}^{\prime} \mathrm{s}$, is similar in operation sys. tem to Shimadzu's automatic winder.

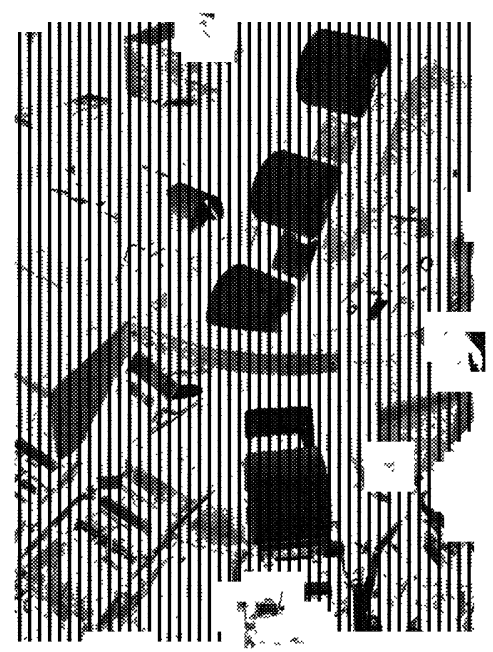

Fig. 5 Murata's No. 10-AW Auto-Doffer

When ACF, the automatic re-knotter and the autodoffer are completed, one operator, it is reckoned, can take care of several machines. However, unless the misoperation of winding head is kept at a reasonably small rate, it will be difficult for one operative to mind more than one automatic winder. The efficiency, particularly of ACF, in picking up yarn ends is easily influenced by the condition of cop supply (Generally, the efficiency rate is $96 \%-98 \%$ ). If we must have $100 \%$ efficiency, it will have bad influence on package, e. g., waste yarn entering the package, as everyone knows.

ACF-D type has been developed with this problem in mind and gives practically $100 \%$ efficiency by supplying to the knotter unit only cops whose yarn ends have been correctly picked up. It has various devices to eliminate irregular cops, to re-feed cops, to pool them with picked ends and to feed cops quickly so as to prevent delay in feeding cops to the units.

This new type of ACF (Automatic Cop Feeder) may not be much needed where one man looks after only one machine. It will be appreciated when a fully automatic cone/cheese winder is put in service to enable one man to attend to more than two machines.

Murata's auto-doffer works similarly to Shimazu's S-AW type automatic winder. The difference between $\mathrm{S}-\mathrm{AW}$ and Murata's No. $10-\mathrm{AW}$ is that S-AW works in the straight parts of the machine, while No. 10-AW works in the turn points just behind the knotter. No. $10-\mathrm{AW}$ has seven sets of saucers in a radial position, synchronizes them with the winding unit and sends full packages in a row on a belt conveyor. The saucers double as emptybobbin suppliers.

Murata's auto doffer differs noticeably from Shimadzu's automatic winder in driving systems (in the manner of receiving full packages, in constructing empty bobbin chucks, in the winding of yarn ends around the tube).

New innovations introduced into Murata's auto doffer include a snarl preventor, a mis-knot cutter, a

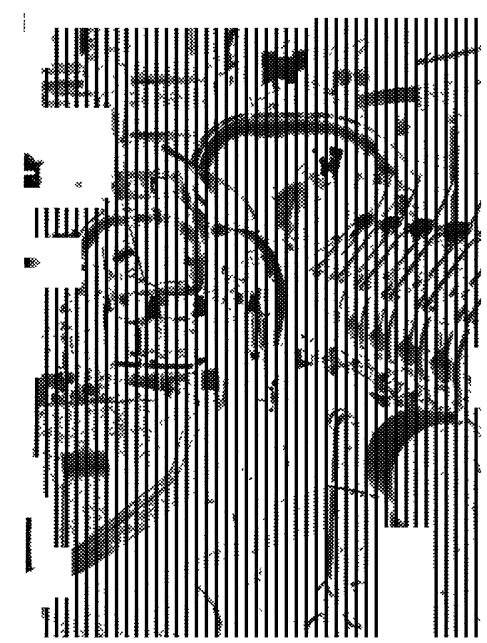

Fig. 6 Murata's No. 10-AW New Type ACF (ACF-D type) 


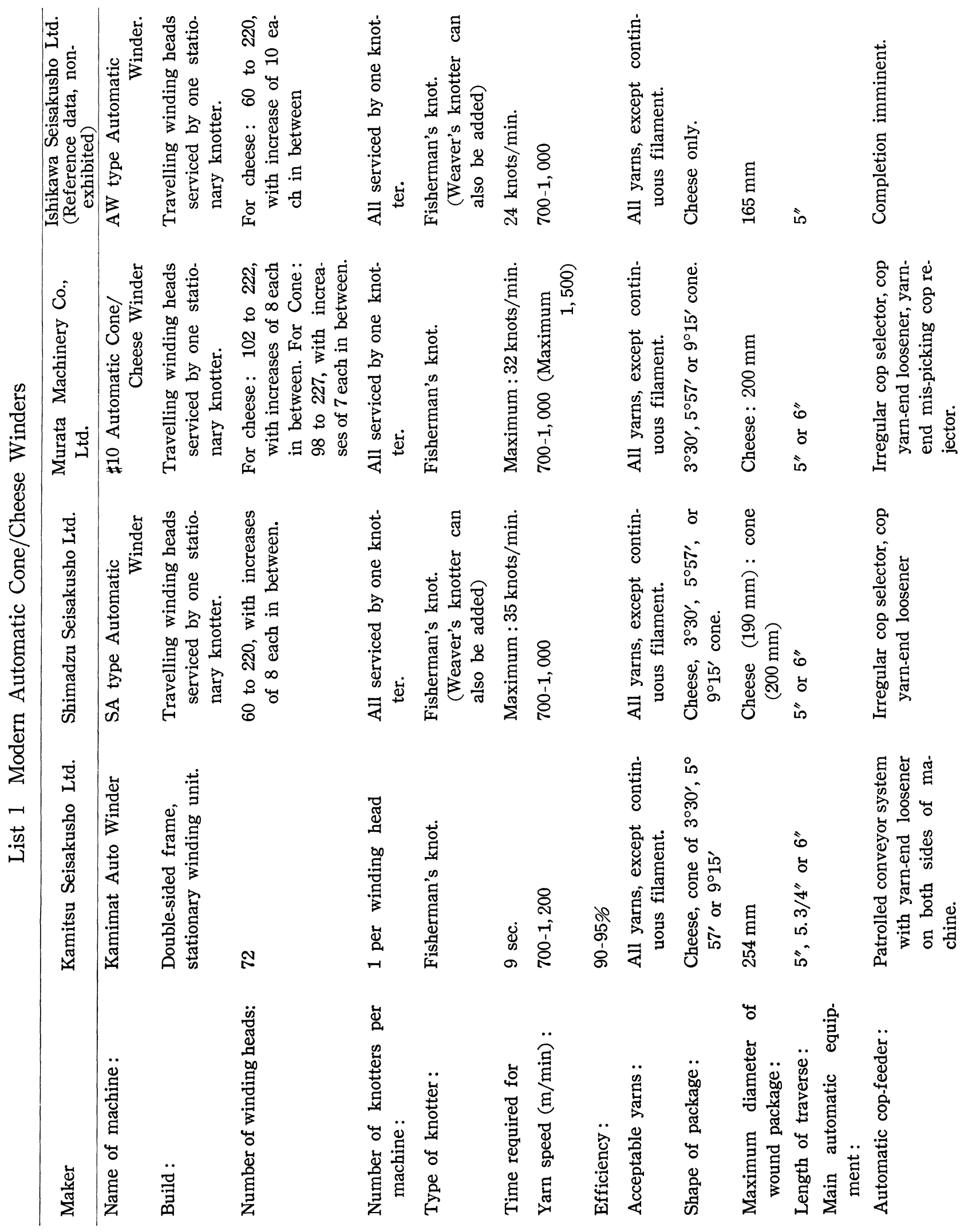



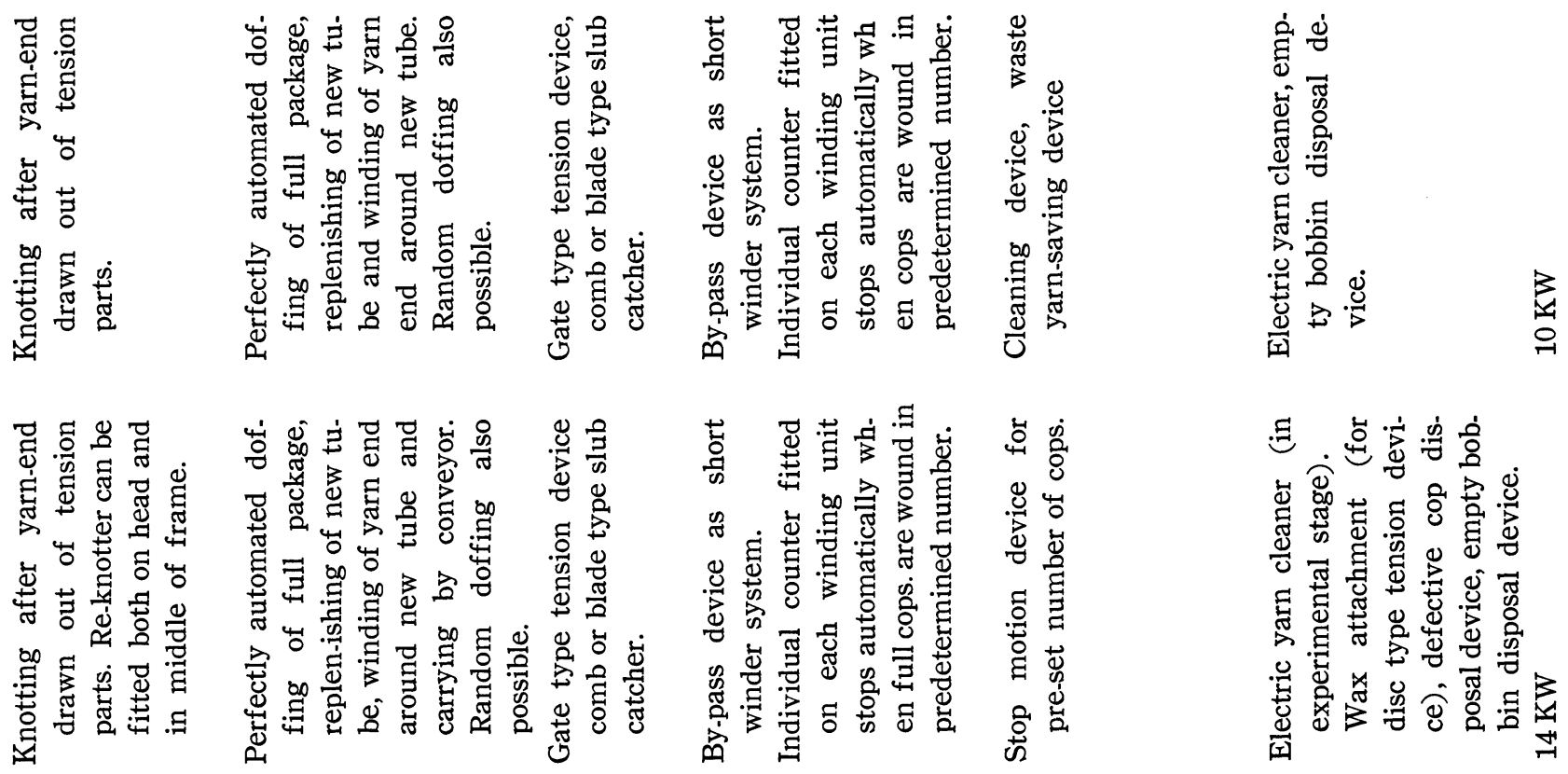

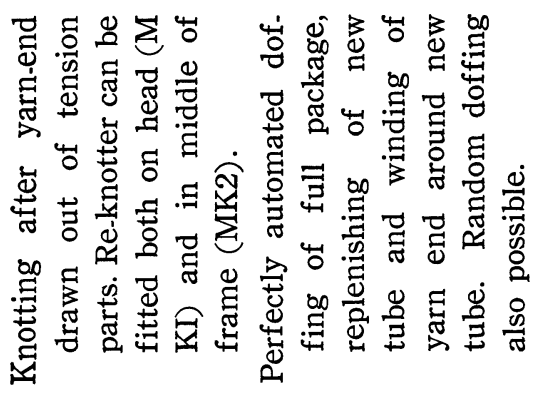
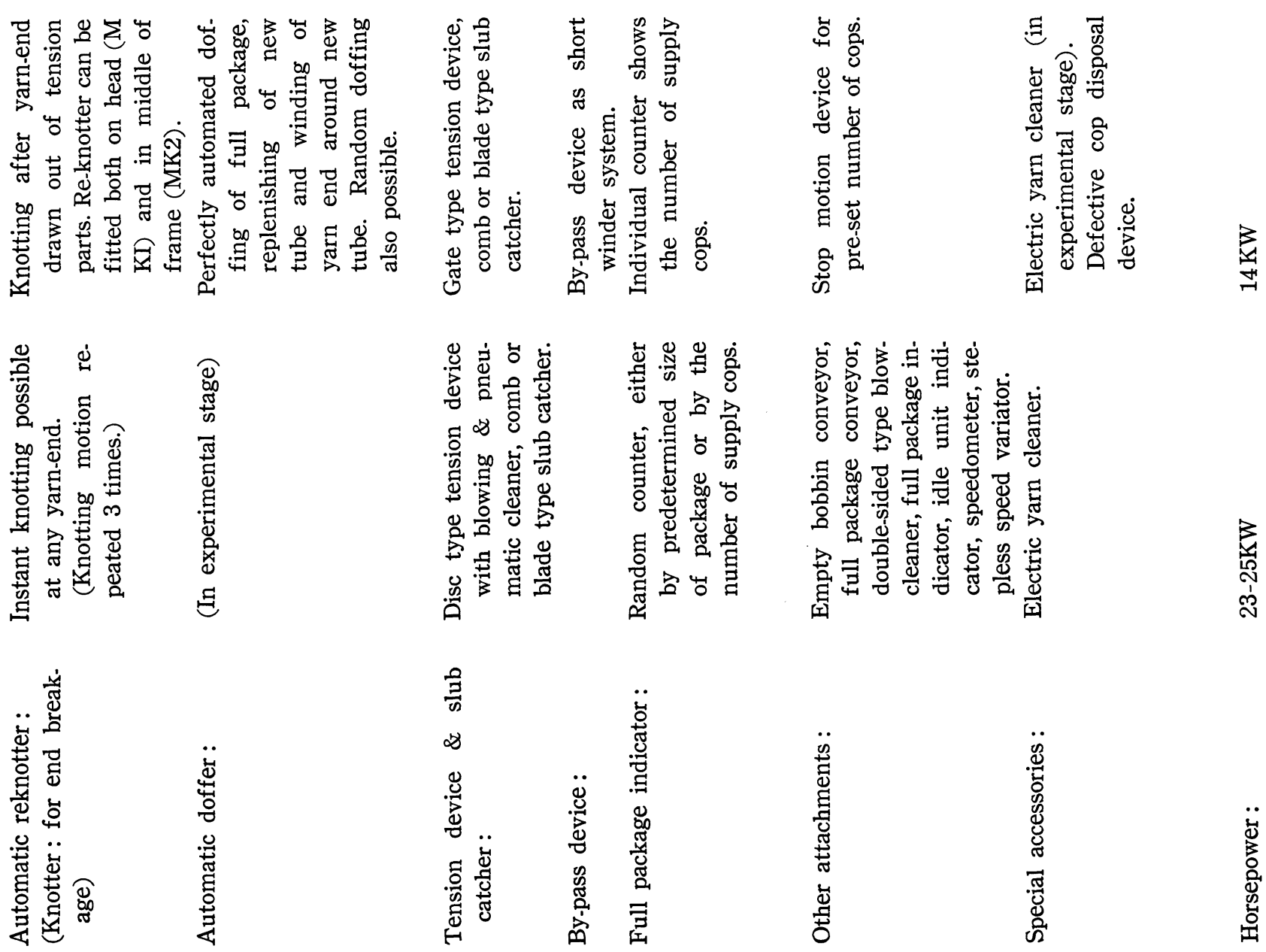
device to put yarn into the knotter, a tension and slub catcher, a cop counter and a slow starter of the drum.

The auto doffer has been increased in rigidity and stability in all parts. Its operation goal is set at more than 35 knots and a winding speed of 1,200 meters per minute. Meanwhile, a special attachment for high-speed winding from the filling cop is in an experimental stage.

\section{(b) Electronic slub catchers}

(4) Uster Automatic

Keisokuki Kogyo., Co., Ltd.

(5) Seletex

Nippon Selen Co., Ltd.

(6) Electro Clean

Neyagawa Kosakusho Co., Ltd.

Optex

Jonan Electric Co., Ltd.

Electronic slub catchers have been rapidly brought to a high stage of development as high-efficiency winders of high-quality yarns. More than 10 types of slub catchers on the photo electricity system and several types on the capacity system have been introduced into the textile industry.

The exhibits at the fair were Uster automatic slub catcher on the capacity system, Seletex, Electro Clean and Optex, all on the photo electricity system. These have been developed by Japanese makers on their own resources or under technical affiliations with foreign makers.

An improved type of Qualitex is now made domestically.

Japanese slub catchers are catching up rapidly with first-rate foreign makes. They vary widely in performance level and price; it is up to the user to choose a slub catcher which suits his purse and the yarn he has to wind.

\section{(c) Precision Winders}

There were more displays of precision winders for filament yarns than at the previons fair, but none radically new. The exhibits were equipped with attachments for minimum requirements. Still, they evidenced efforts at high-quality packages, high-speed winding and large packages. Higher machine quality, greater facility of handling and longer durability are among the future improvements desired.

The exhibits were:
(1) Ishikawa-Schweiter KE-25

(2) Ishikawa-Schweiter KEK. PN200

(3) Ishikawa-Schweiter KM (Cross Winder)

(4) Kamitsu SP (5) Murata No. 56

$\begin{array}{ll}\text { (6) Torii No. } 66 & \text { (7) Torii No. } 158\end{array}$

Nos. 3, 4 and 7 had been previously introduced in this Journal and showed no changes.

\section{(8) Ishikawa-Schweiter KE-25}

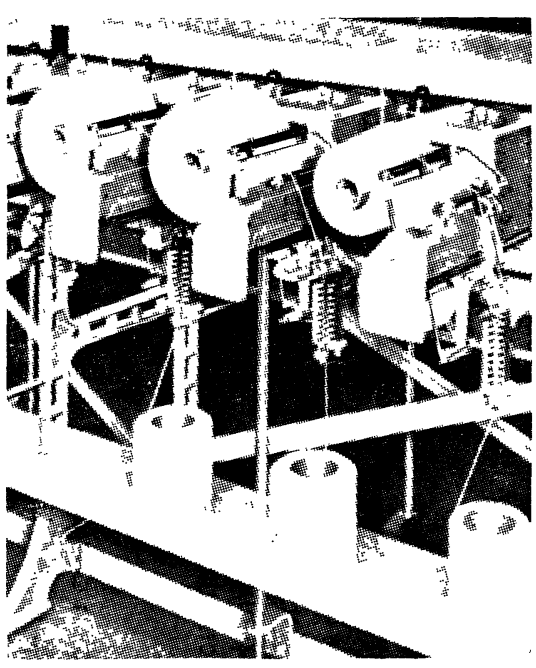

Fig. 7 Ishikawa-Schweiter KE-25

\section{(9) Ishikawa-Schweiter KEK. PN200}

Nos. 8 and 9 were displayed for the first time at the fair. Both are manufactured under a technical tie-up with Schweiter Co., Ltd. No. 8 is for large packages and has straight edges for coarse-denier yarns. No. 9 is for large packages of fine denier. They are stabilized in performance like schweiter's other wellknown cone/cheese winders.

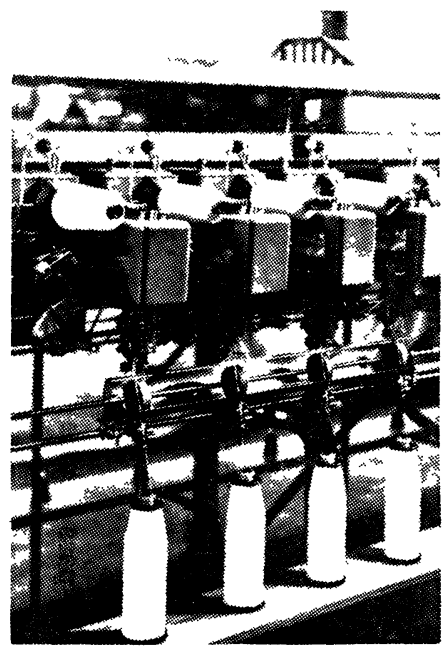

Fig. 8 Ishikawa-Schweiter KEK. PN 200 


\section{(10)}

\section{Murata's No. 56 Texmat}

No. 55 A Filmat which had been exhibited at the Atlantic City Fair attracted the notice of millmen as an all-purpose machine of high working efficiency. No. 56 Texmat has been manufactured with emphasis on quality. It is considered equal in efficiency to Ishikawa-Schweiter type KEK. Its major features include a compensator for the feed roller parts, a onetouch type starting handle and a hank-swift arrangement. Ingenuous efforts at large packages and adjustment of the position of the driving shaft are clearly noticed.

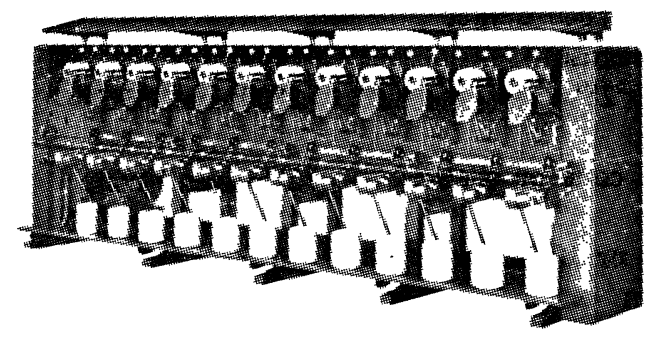

Fig. 9 Murata's No. 56 Texmat

\section{(11) TS-66 Uuiverse Coner}

\section{Torii Winding Machine Co., Ltd.}

This winder incorporates many interesting new systems to meet the need for high-speed winding and soft winding.

1. Spindle-driving

The spindle is driven by a cam shaft through a friction pulley having a synchro belt, which is driven by the main shaft. The maximum speed of the spindle is 3,000 RPM for three winds and 2,000 RPM for two. It is an increase of $70 \%$, over the conventional winder of the corresponding type.

2. Reducing the number of spindle revolutions

A semispherical, variable-speed pulley is fixed between the friction pulley of the main shaft and the cam-shaft-driving pulley. The angle of contact of the variable-speed pulley and the pulley is varied with the growth of the winding package to reduce the number of spindle revolutions gradually. This reduces the number of spindle revolutions more than does the con. ventional plain disc.

3. Changing the number of winds

Seven different numbers of winds in a range of 3. 2-2. 0 are obtainable by changing synchro-pulleys and synchro-belts.

4. Feed roller

Vol. 12, No. 6 (1966)
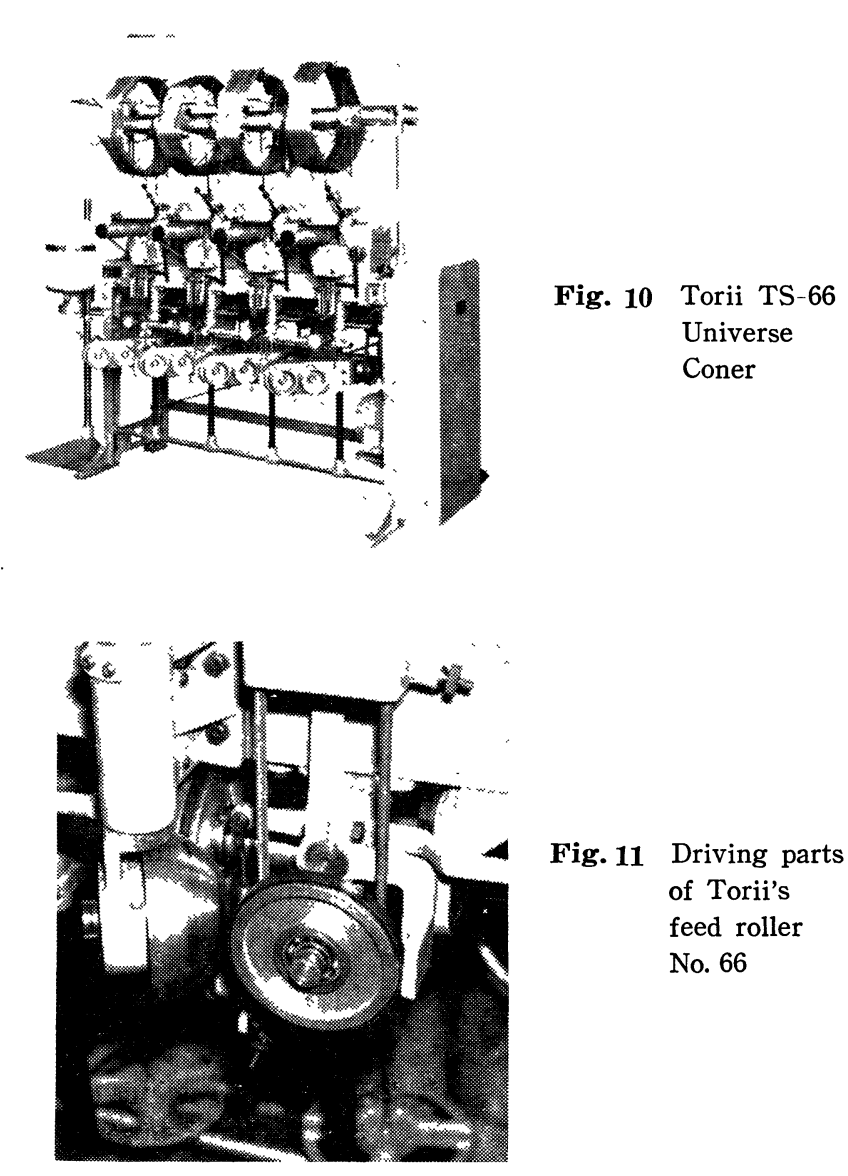

The feed roller of the conventional machine is driven by the spindle shaft. The feed roller of TS-66 is driven directly from the main shaft by a V-belt.

The over-feeding speed of the feed roller is always kept constant. The feed roller moves in a link motion with the starting and stopping of the spindle. The feed roller is placed at about $45^{\circ}$ to the gate-tenser to facilitate yarn supply.

5. Changing the taper degree of wound package.

The angle at which the cam case is set can be freely changed in a range of $0^{\circ} 0^{\prime}$ to $4^{\circ} 20^{\prime}$, because the cam shaft is connected to the universal joint.

Package shapes ranging from $0^{\circ} 0^{\prime}$ to $4^{\circ} 20^{\prime}$ in taper are obtainable by changing bobbin holders.

6. Positive system of pressure-reducing

By spindle revolutions, the cradle holding the spindle is separated at a constant ratio from the contact roll which is on the side of cam box frame. The pressure of contact between the surface of the package and the contact roll is positively reduced by repeating this motion. The separating distance is adjustable to the type of yarn by the adjust-cam placed on the outside of the case. 
List 2 Cone/Cheese Winders

$\begin{array}{lll}\text { Maker: } & \text { Torii Winding Machine } & \text { Torii Winding Machine } \\ \text { Co., Ltd. } & \text { Co., Ltd. } & \text { Murata Machinery Ltd. }\end{array}$

1. Name of Machine: TS-66, Universe Coner

2. Build :

3. Standard number of spindles :

4. Acceptable yarns :

5. Type of wind :

6. Taper of cone :

7. Shape of wound package :

8. Length of traverse :

9. Maximum diameter of wound package :

10. Maximum weight of wound package :

11. Number of winds :

12. Spindle revolutions (RPM) :

13. Spindlerevolution reducer :

14. Tension device :

15. Feed roller :

16. Yarn-supplying :

17. Pressure system :

18. Automatic stop motion device :

19. Oiler :

20. Creeping device:

21. Others :

22. Horsepower :
Spindle-drive

6

Filament yarns (including bulky \& spandex yarns) up to 300 denier

Open

$0^{\circ} 0^{\prime}, 0^{\circ} 30^{\prime}$ or $4^{\circ} 20^{\prime}$

Cheese, cone or taper-end cone

$152 \mathrm{~mm}$ or $127 \mathrm{~mm}$

$178 \mathrm{~mm}$

2 or 3

2,000 (for 2 winds): or 3,000 (for 3 winds) spherical surface disc

Gate type tension device with release attachment \& automatic compensa. tor for irregular tension.

Attached. Synchronous with yarn speed.

Over-end or hank supply.

Possitive system of pressu re reducing $0-1 \mathrm{kgs}$.

Yarn-breakage, Full package.

Attached.

Attached.

Good for dyeing

1. $5 \mathrm{KW} / 12$ spindles
Filament yarns (including bulky \& spandex yarns) 70 30, 000 denier

Open, Close

$0^{\circ} 0^{\prime}-9^{\circ} 15^{\prime}$

Square cone or cheese

$6,7,8$ or 10 inches $292 \mathrm{~mm}$

$1-15 \mathrm{kgs}$.

2,3 or 4

1,800

variable-pitch disc

Gate type tension device with release attachment, combined with dancing roller.

Attached. Synchronous with yarn speed.

Over-end or hank supply.

Negative

Yarn-breakage, Full package.

Attached.

Non.

$200 \mathrm{~W} /$ spindles
No. 56 Texmat

Spindle-drive

12

Filament yarns (including bulky \& spandex yarns)

Open

$3^{\circ} 30^{\prime}$ or $3^{\circ} 51^{\prime}$

Taper-end cone

$152 \mathrm{~mm}$

$160 \mathrm{~mm}$

1 kgs.

3.2

$1,200-1,750$

plain disc

Gate type tension device with release attachment.

Attached.

Muff, hank, pirn, cheese and doubling-twisting bobbin, etc.

Negative

Yarn-breakage, Full package.

Attached (double-roller type speed controller)

Attached.

Slow starter \& brake for hank-winding. Pressuredetaching device.

1. $5 \mathrm{KW} / 12$ spindles. 
Kamitsu Seisakusho Ltd. Ishikawa Seisakusho Ltd. Ishikawa seisakusho Ltd. Ishikawa Seisakusho Ltd.

\begin{tabular}{|c|c|c|c|}
\hline SP Precision Winder & KE-25, Cone Winder & KEK-200 Cone Winder & KM Vario-Coner \\
\hline Spindle-drive & Spindle-drive & Spindle-drive & Surface (drum)-drive \\
\hline $\begin{array}{l}5,10,15 \& 20 \text { for } 8^{\prime \prime} \& \\
10^{\prime \prime} \text { traverses } \\
6,12,18 \& 24 \text { for } 6 " \text { tra- } \\
\text { verses }\end{array}$ & $\begin{array}{l}8,12,16 \text { or } 32 . \\
\text { (double sided) }\end{array}$ & $\begin{array}{l}8,12,16,20,24,32,40 \text { or } \\
48\end{array}$ & 8,16 or 32 \\
\hline \multirow[t]{2}{*}{$\begin{array}{l}\text { Filament yarns (including } \\
\text { bulky \& spandex yarns) } \\
\text { 15 2, } 000 \text { denier }\end{array}$} & $\begin{array}{l}\text { Filament yarns (including } \\
\text { bulky \& spandex yarns) } \\
75 \sim 1,000 \text { denier }\end{array}$ & $\begin{array}{l}\text { Filament yarns (including } \\
\text { bulky \& spandex yarns) }\end{array}$ & $\begin{array}{l}\text { Spun or filament yarns } \\
\text { (including bulky and } \\
\text { spandex) }\end{array}$ \\
\hline & Open & Open & Open \\
\hline $\begin{array}{l}0^{\circ} 0^{\prime}, 3^{\circ} 30^{\prime}, 3^{\circ} 51^{\prime} 5^{\circ} 57^{\prime} \text { or } \\
7^{\circ} 0^{\prime}\end{array}$ & $3^{\circ} 30^{\prime}$ & $3^{\circ} 30^{\prime}$ & $3^{\circ} 30^{\prime}$ or $9^{\circ} 15^{\prime}$ \\
\hline $\begin{array}{l}\text { Cheese, square or taper- } \\
\text { end cone }\end{array}$ & Square-end cone & Taper-end cone & Increased taper cone \\
\hline $152 \mathrm{~mm}$ or $254 \mathrm{~mm}$ & $150 \mathrm{~mm}$ & $200 \mathrm{~mm}$ & $150 \mathrm{~mm}$ \\
\hline $200 \mathrm{~mm}, 300 \mathrm{~mm}$ & $220 \mathrm{~mm}$ & $150 \mathrm{~mm}$ & $250 \mathrm{~mm}$ \\
\hline $8 \mathrm{kgs}$. & $4.0 \mathrm{kgs}$. & $1.5 \mathrm{kgs}$. & $2 \mathrm{kgs}$. \\
\hline 2.5 or 3.2 & 1.7 or 2.2 & 3.2 & 3.2 \\
\hline 2,500 & $650-1,150$ & $1,200-1,750$ & $200-400 \mathrm{~m} / \mathrm{min}$ \\
\hline plain disc & plain disc & plain disc & \\
\hline
\end{tabular}

Gate type tension device with release attachment. Disc type tension for coarse denier yarn.

Gate type tension device with release attachment.

Gate type tension device with release attachment.

Gate or disc type tension device.

Attached.

Over end. Attached.

Attached.

\section{Negative \\ Yarn-breakage, Full package. \\ Yarn-breakage, Full packa- ge.(Electric type device) \\ Negative}

Attached.

Cheese, over-end, hank, or Over-end, or hank. muff.

Negative
Yarn-breakage, Full
package.
Attached.

Attached.
Negative

Yarn-breakage, Full package.

Attached (Waxing attach. ment is also fitted). Attached.

For Knitting yarn 


\section{Other devices}

The creeping device and the non-bending guide for supply yarn are well-designed. TS-66 is a good winder easy to use, but it has some elements which complicate its mechanism. Its final evaluation must a wait the results of its future service.

\section{(d) Doubling \& twisting machine}

\section{(12) Ishikawa's DTB Type High Speed Double Twister}

\section{Ishikawa Seisakusho, Ltd.}

At the fair, Ishikawa came out with a new type of double twister having a double taper-build system, instead of the ordinary taper-top build system. Otherwise this double twister does not differ from the old type.

The double taper-build gives many advantages. One is that it carries the pirn intact in its shape without the need for the next winder. Another is that it uses the pirn tube of the original yarn, instead of a bobbin or paper tube, and packs the pirn bobbin again into the pirn box which has been used to carry the original yarn.

There are several types of double taper-build systems, such as the filling, warp and the compound types. They can be easily fitted to the existing machine merely by replacing the old-type building device with new. The new double twister is changed in lift from 9 inches $(229 \mathrm{~mm})$ to 10 inches $(254 \mathrm{~mm})$ to avoid a decrease in the quantity of the pirn wound.

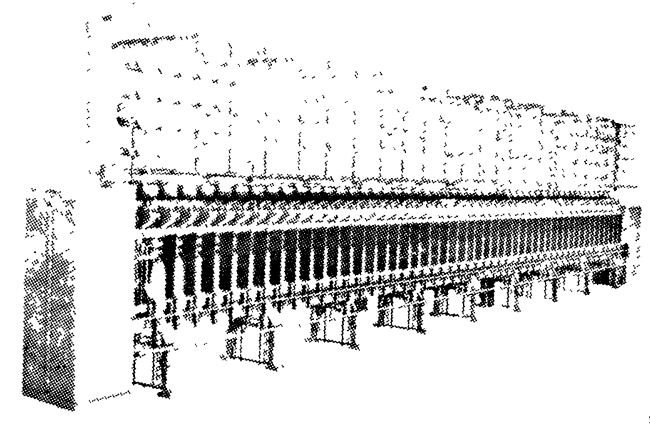

Fig. 12 DTB Type High Speed Double Twister

\section{(13) Toshiba R-105 Type High Speed Double Twister}

Toshiba Machine Co., Ltd.

This machine can be used for double twisting yarns to make large packages at a high speed. It does not differ much in mechanism from Ishikawa's DTB type double twister. One of its advantages is its feed roller which is capable of a maximum speed of $450 \mathrm{M}$ / min. The lift of its winding pirn is large. It is particularly good for loose twisting. The twister makes four-end doubling. The standard shape of package is the straight wind or taper-top-wind, but it can be changed easily to the double-taper-wind by replacing the building motion device.

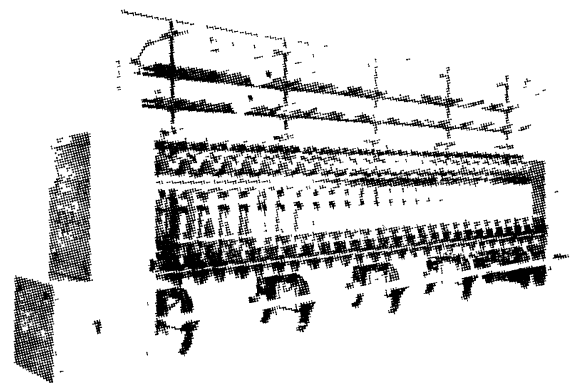

Fig. 13 R-105 Type High Speed Double Twister

\section{(e) Up-Twister}

Japan has more than 10 makers of up-twisters, but the only exhibit at the fair was Iwasho's HP-300 type. At foreign exhibitions, too, Up-Twisters on show have been much smaller in number than ring twisters and double twisters.

One reason is undoubtedly that up-twisters cannot do reverse-twisting or hard twisting. Besides, they cannot make as many spindle revolutions (actual twisting speed) as double twisters but consume more power. However, up-twisters have their own merits, and every maker is trying to remedy their shortcomings. HP$300 \mathrm{H}$ is an example of such efforts. We hope we shall see an up-twister of much higher efficiency.

\section{(14) Iwasho's 300H Type Up-Twister}

\section{Iwasho Loom Works Co., Ltd.}

This exhibit had a heater, which an ordinary up[twister has not, for setting the twist between the spin-

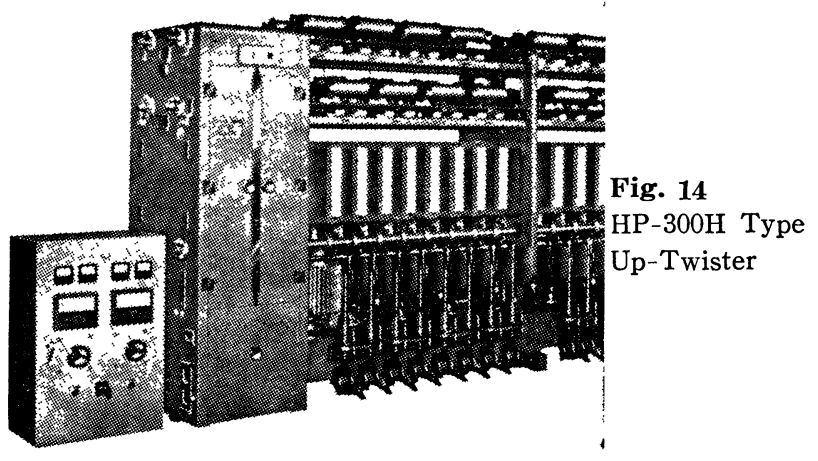


List 3 Specifications of Doubling Twisters

\begin{tabular}{lll}
\hline Maker & \multicolumn{1}{c}{ Ishikawa Seisakusho Ltd. } & \multicolumn{1}{c}{ Toshiba Machine's Co., Ltd. } \\
\hline Name of twister & Ishikawa DTB Type High Speed & R-105 Type High Spped Double \\
& Double Twister. & Twister. \\
Number of spindles & 100 spindles & 100 spindles \\
Spindle gauge & $178 \mathrm{~mm}(7$ inches $)$ & $178 \mathrm{~mm}$ \\
Lift & $203,229 \& 254 \mathrm{~mm}$ & $267 \mathrm{~mm}$ \\
Diameter of ring & $127 \mathrm{~mm}$ (up to $133 \mathrm{~mm})$ & $127 \mathrm{~mm}$ \\
RPM of spindle & $4,000-9,000 \mathrm{RPM}$ & $5,000-10,000 \mathrm{RPM}$ \\
Yarn speed & $50-2,000 \mathrm{TPM}$ & Max. $450 \mathrm{M} / \mathrm{min}$. \\
Number of twists & $\mathrm{S}, Z$ & $20-800 \mathrm{TPM}$ \\
Direction of twisting & $1-8$ ends & $\mathrm{S}, \mathrm{Z}$ \\
Number of doubling ends & $1.2 \mathrm{kgs}$ & 4 ends \\
Weight of package & Taper-top, warp, filling double- & $1-1.5 \mathrm{kgs}$ \\
Shape of package & taper-compound. & \\
\hline
\end{tabular}

dle and the take-up. Filament yarn can be set, during heating, by adding a delivery roller. This makes dyeing possible while cheese-up is retained. Michel Ratti (Italian make) is based on the same principle.

The feed roller is used not as a common over feed but as a means to put about $7 \%$ draft, thus making hard twist $(1,800-2,000 \mathrm{RPM}$.) possible. This is one of the big features of the machine. Much ingenuity has been put into the taking-up device, the heater, etc.

List. 4 Specifications of Iwasho $300 \mathrm{H}$ Type Up-Twister.

Type of machine: Single-sided frame, with one-step heater.

Build : $\quad$ Twisting by spindle and winding up by cylinder.

Number of spindles : 96,64

Driving motor: $96 \mathrm{sp}-11 \mathrm{KW}, 64 \mathrm{sp}-7.5 \mathrm{KW}$

RPM of Spindle: 6, 000-15,000 RPM

Number of twists : 100-2,000 TPM

Shape of package: Conical ends. Maximum angle of edge : $45^{\circ}$

Weight of package $: 1.5 \mathrm{kgs}$.

Traverse

i) Length of traverse: $200 \mathrm{~mm}$ (including length of traverse displacement)

ii) Traverse displacement:By differential gears.

iii) Number of winds : 7 (standard)

Delivery speed :

By a system which varies the number of revolutions of driving drum.

Heater : Ceramic heater, or heater with heating board.

Yarn breakage stopper: Cradle and delivery stop together.

\section{(f) Double Twisters}

Ishikawa's, Tsudakoma's and Toshiba's twisters for filament yarn were shown at the fair. Ishikawa's for spun yarn was displayed for the first time.

Until last year, double twisters from various makers were conspicuous by their relative merits and demerits. This has changed. Efforts at improved work. manship even in minor details have produced twisting parts which all deserve worldwide notice.

New ideas have been introduced also into the winding parts which remained largely standardized with only lukewarm efforts made at improvement. The exhibits showed that there had been general efforts at higher efficiency and higher quality - better stop motions, larger packages. Tsudakoma's exhibit, a model change, attracted notice because it was a definite improvement on the old model.

Foreign double twisters for spun yarns are being widely advertised, but Ishikawa's Barmag was the only foreign entry in the fair. It is an excellent machine (Figs. 18-20) with an established reputation. It is scheduled to go into production in Japan shortly before an expectant Japanese textile industry. Meanwhile, several Japanese manufacturers have double winders in an experimental stage.

\section{(15) Tsudakoma TO-2 Type Double Twister Tsudakoma Industrial Co., Ltd.}

TO-2 Type is an improvenent on TO-1 Type. Here are its main features :

1. Type of ballooning.

TO-2 Type has two types of ballooning systems : multiple-ballooning for low tension and single-ballooning for high tension. The ballooning is quite good to 
look at.

2. Weight of package.

The weight of package has been increased to 1.5 kgs. (other makers' is $1 \mathrm{~kg}$.)

3. Take-up device.

Handling is easier because the tube is held in a lower position. Unevenness of tension is absorbed
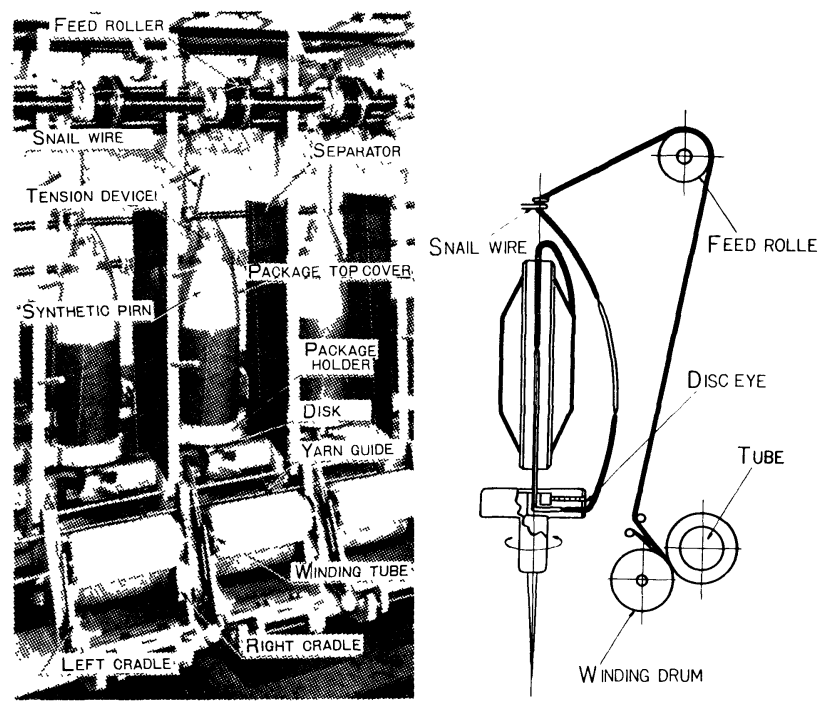

Fig. 15 TO-2 Type Double Twister

Fig. 16 Tsudakoma's TO-2 type Doubling Twister

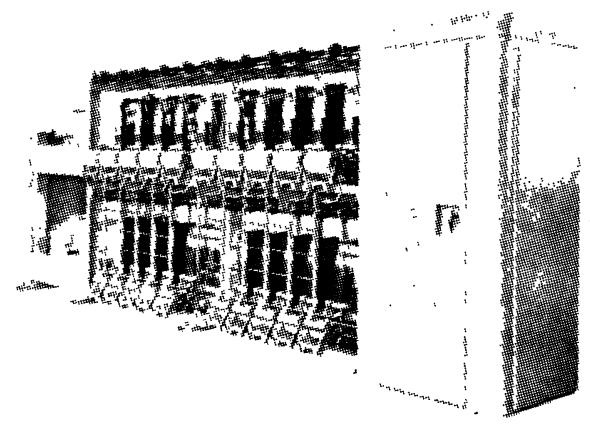

Fig. 17 Tsudakoma's TO-2 type Doubling Twister

more easily because the distance from the feed roller to the winding parts has been increased slightly. The pirn-forming system has been changed from the spindle-for-spindle, individual system to an all-spindle system, although the general preference seems to be for the old (individual) system.

4. Automatic stop motion device.

TO-2 type is probably the first double twister equipped with a spindle-stopping motion linked to a take-up device and with a breakage detecting lever of an automatic-reverting type.

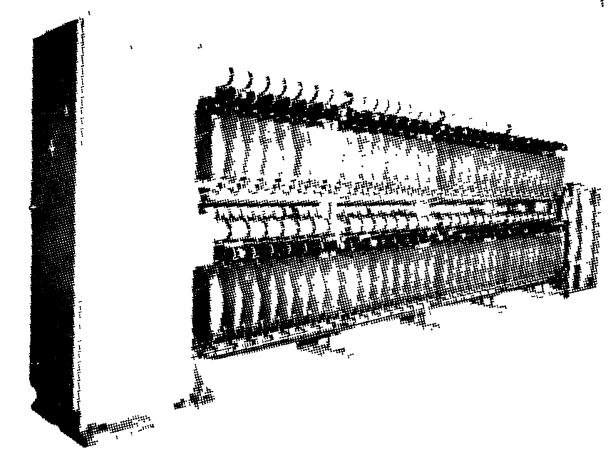

Fig. 18 Ishikawa's Barmag DD-25 Doubling Twister

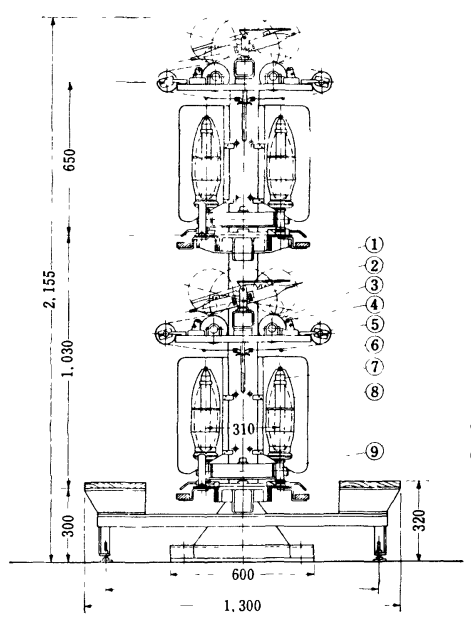

1. Take-up cylinder

2. Cradle

3. Winding drum

4. Traverse motion

5. Over-feed roller

6. Thread guide

7. Magnet tension washer

8. Pirn holder

9. Spindle

Fig. 19 Ishikawa's Barmag DD-25 type Doubling Twister
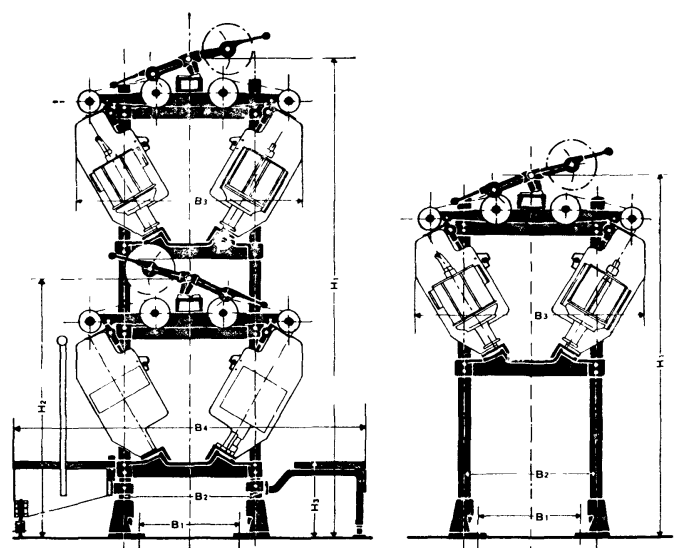

Fig. 20 Ishikawa's Barmag DD-30 type Doubling Twist

\section{(g) Take-up winder}

Torii Winding Machine Co., Ltd. displayed four types of take-up winders :

TS-35B, TS-36, TS-40, TS-130 


\section{(h) Pirn winders, etc.}

Four makers showed six pirn winders, five of them automatic, including Kamitsu's NN auto-pirner which made its debut. Three makers exhibited good machines made on their own resourses. The fourth maker, Meiji Kikai Co., Ltd., entered a bobbinless winder.

Now that more and more looms have a box-loader, pirn winders are equipped with a tip-bunch device and an automatic stacking device and are shaped, in the middle, to be parallel to the box for the free movement of cops in it. Today's pirn winders, having a non-touch building motion, can take both spun and filament yarns. Not only that, we see more and more pirn winders carefully designed to reduce breakage of filling during weaving which hurts weaving efficiency, produces irregular cops and, therefore, impairs yarn quality.

These improvements, made on prodding by users, deserve credit as benefiting the textile industry greatly. Worthy of special mention is KOA's air catch pirn winder which features a special way of disposing of base bunch: the traverse motion starts after the win-

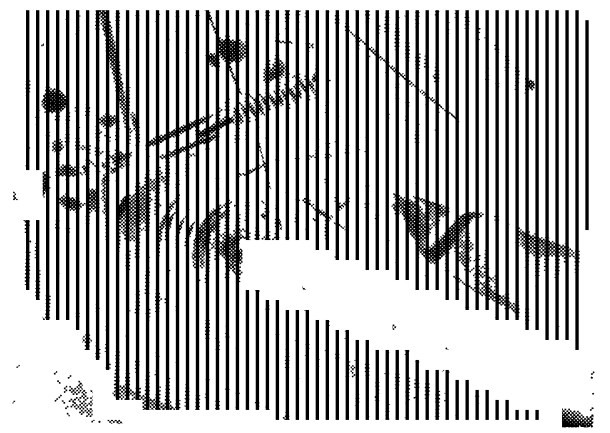

Fig. 21 Yarn-end catcher_of KOA-ACH type air catcher

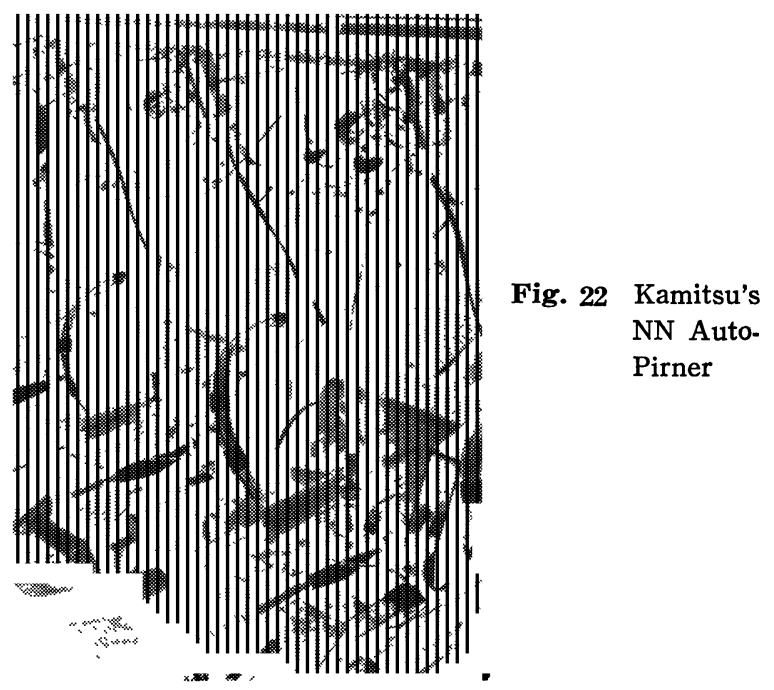

der has drawn yarn-ends into the side hole of the bobbin by vacuum preparatory to winding.

Kamitsu's NN auto-pirner is unique, featuring a traverse guide which guides the yarn by revolving a plate cam; a non-touch system which shifts the traverse motion by detecting the blowing pressure of the air-micro system; an individual and independent motor for each spindle; and automatic operation by a switch solenoid driven by another individual motor.

\section{(16)}

\section{KOA-ACH type Air-Catch Pirn-Winder KOA Spinning Machinery Co., Ltd.}

This winder is for automatic looms having a superloader. It has a tip-bunch and stacking and empty bobbin-supply devices. Its notable feature is its airsuction system for catching yarn ends 'of base-bunch.

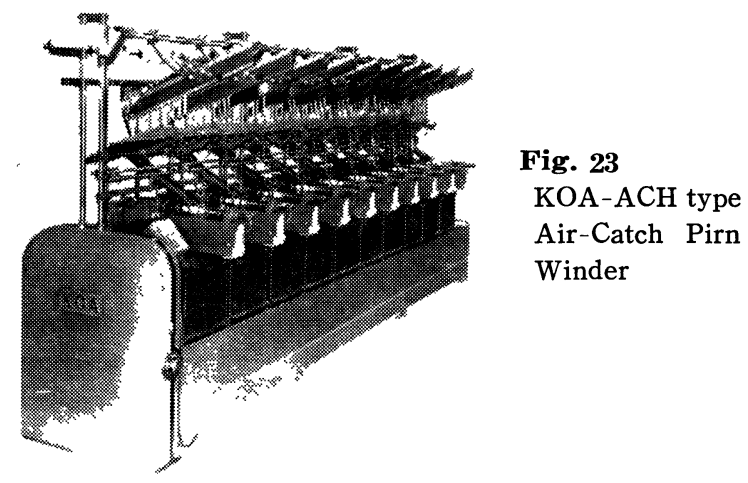

\section{(17) KOA Auto-Pirner}

This winder is a change from the ordinary multispindle pirner to a six-spindle machine. Otherwise it is not new.

\section{K.-1 type High-Speed Bobbinless Winder}

Meiji Kikai Co., Ltd.

Being bobbinless, cops can wind 2.5 to 3 times more yarn than ordinary bobbin cops can. Unwinding tension on this machine is small and even. Cop replacement is not possible and spindle revolutions are only 3,000 to $6,000 \mathrm{RPM}$. There is much room for improvement bebore mass-production can be started.

\section{Kamitsu's NN Auto-Pirner}

Kamitsu Seisakusho Ltd.

This winder has an individual motor per spindle, so that each spindle is driven independently and can, 


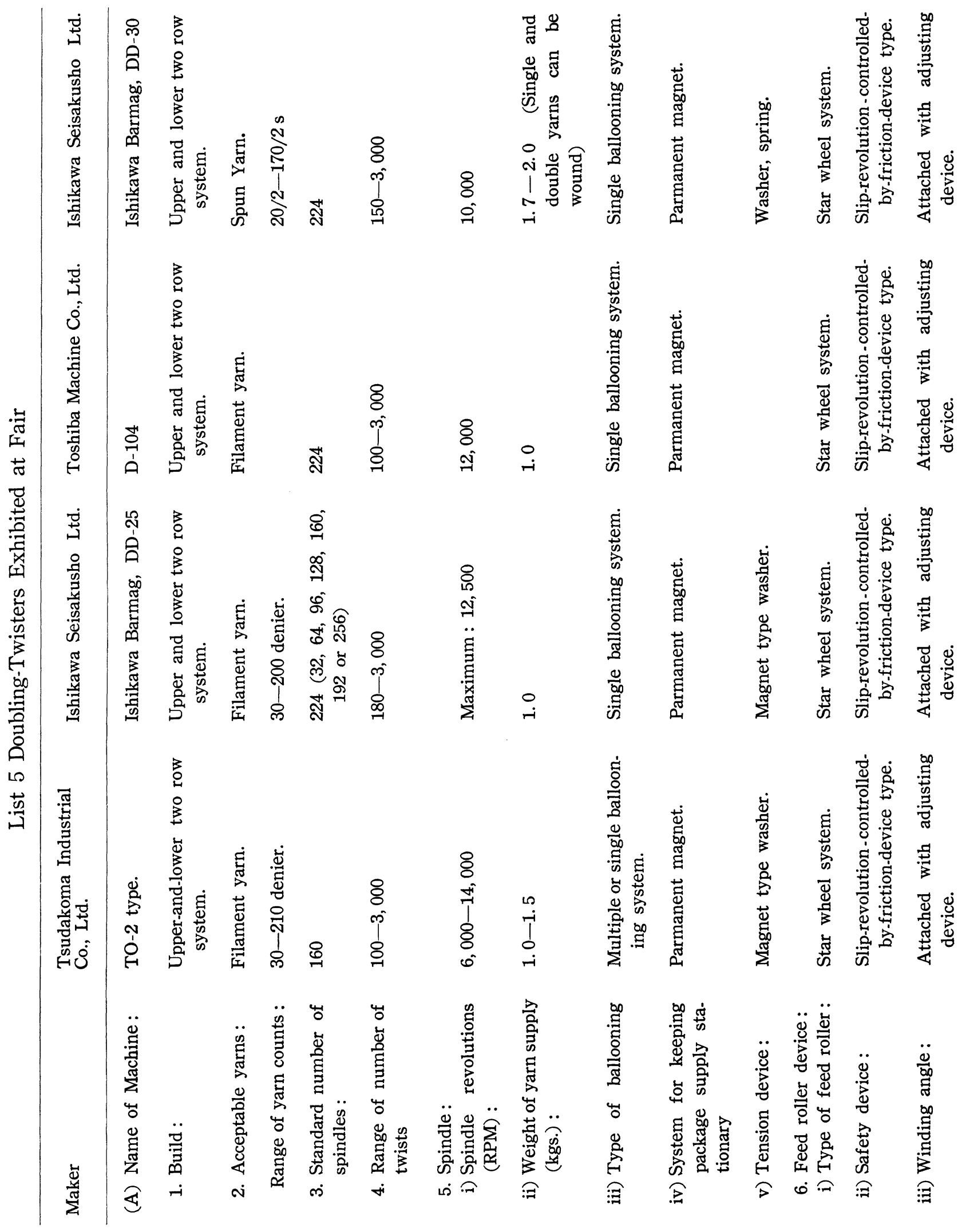



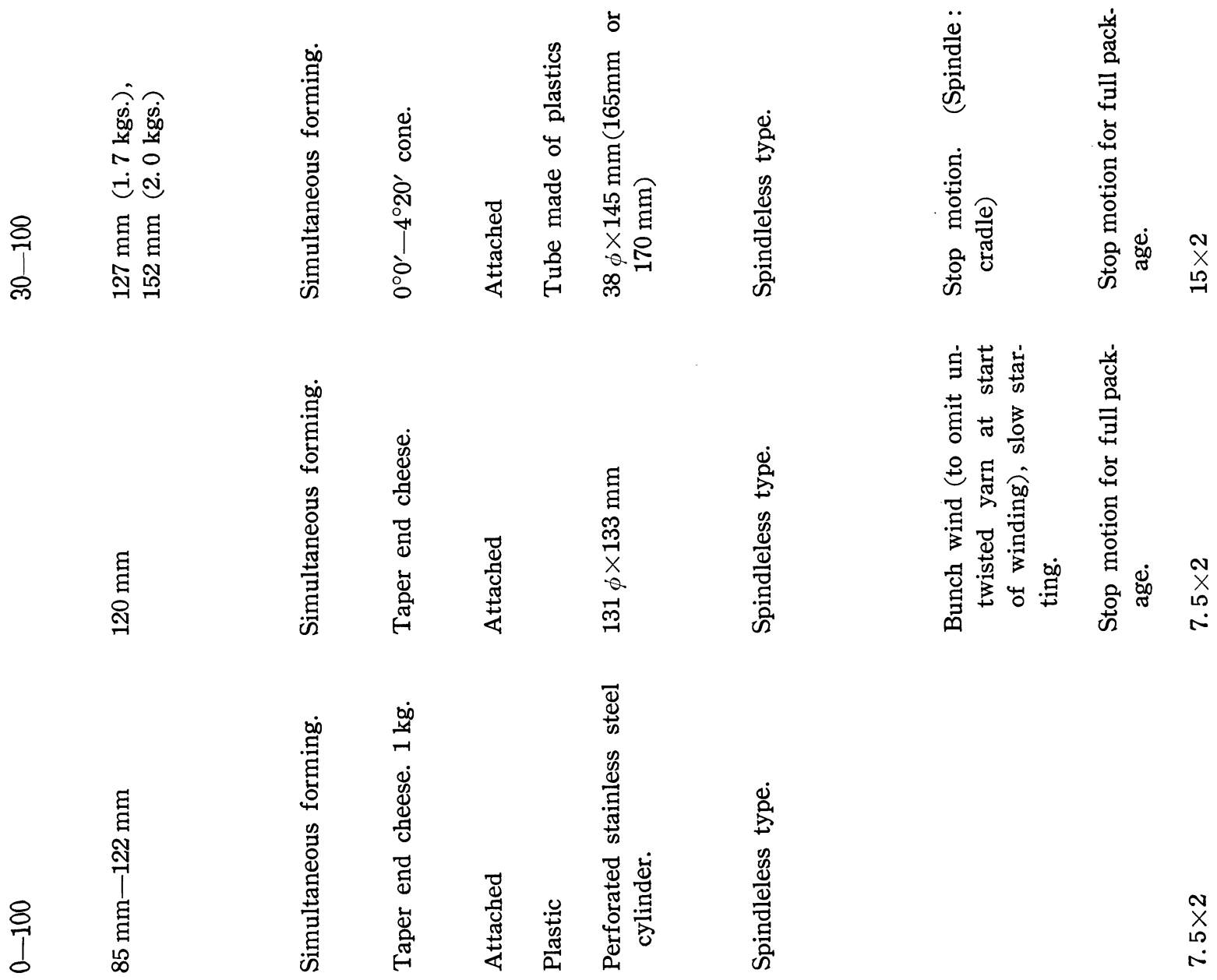

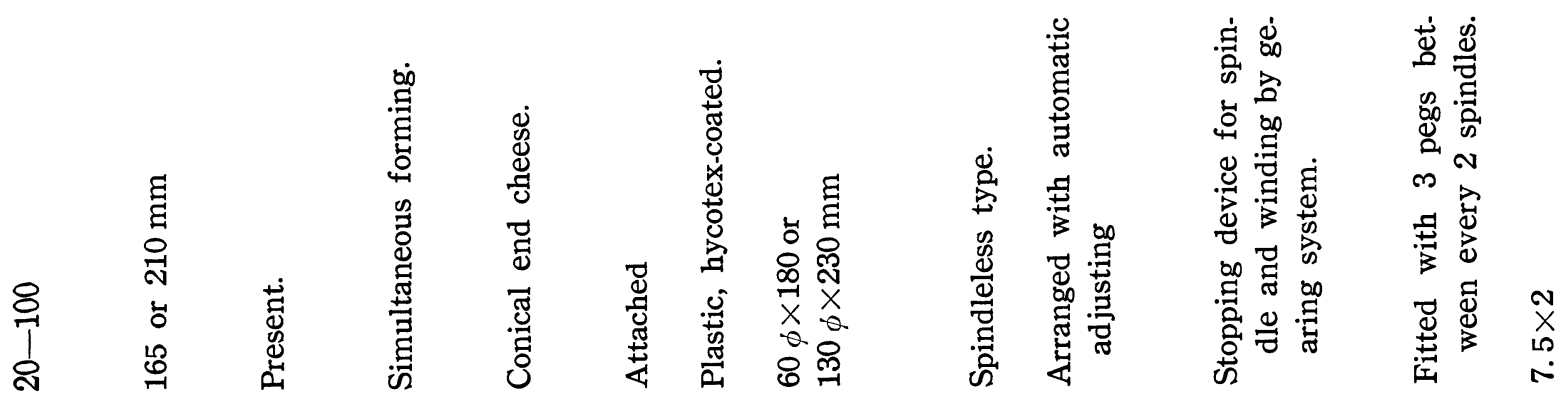

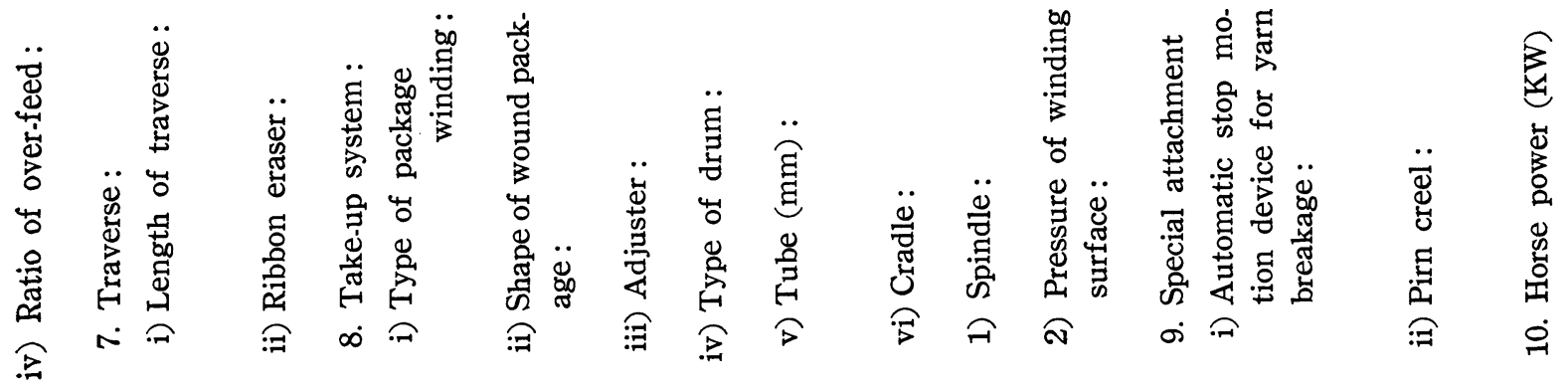




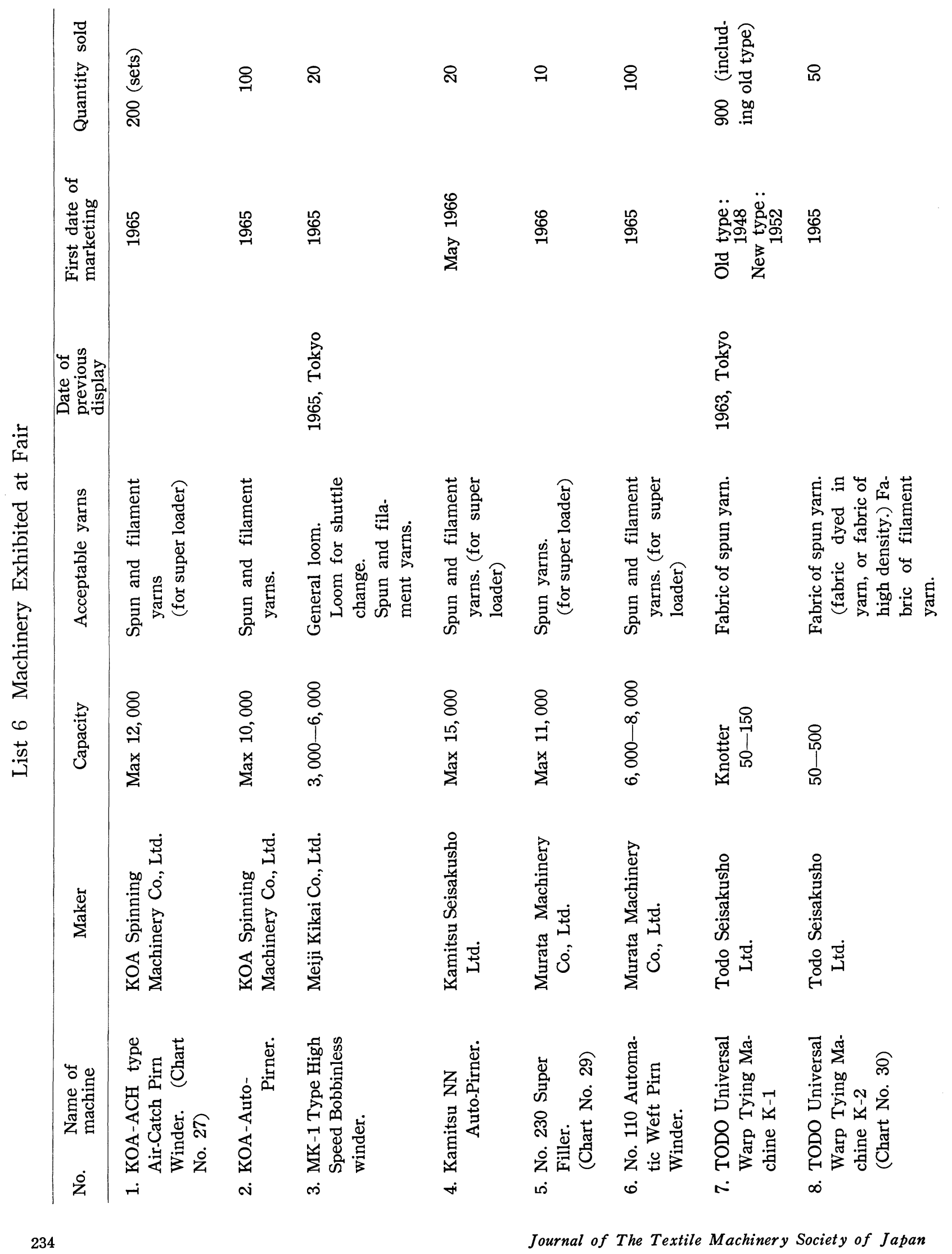


therefore, wind different yarns at the same time on the same machine. It is worth the price asked. Other features are its traverse device and empty bobbin supply device, referred to earlier in this chapter.

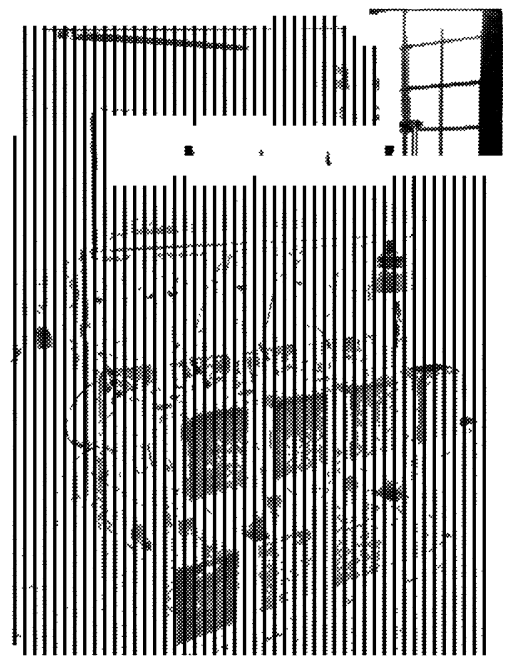

Fig. 24

Kamitsu's NN Auto Pirner

(20)

\section{No. 230 Super Filler}

\section{Murata Machinery Ltd.}

This winder has stacking and tip-bunch devices and is for super loaders.

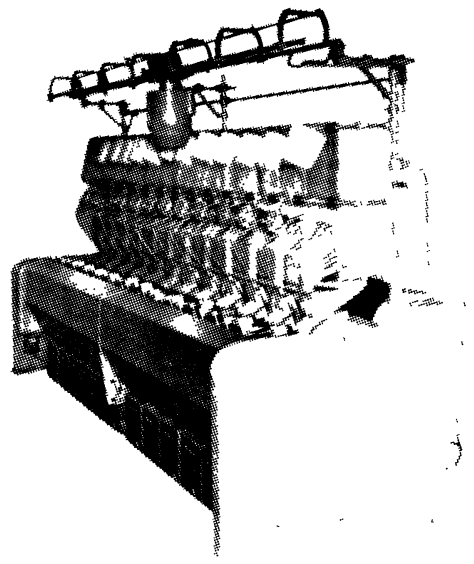

Fig. 25

* 230 Super Filler

\section{(21) No. 110 Super Automatic Weft Pirn Winder}

Murata Machinery Ltd.

This four-spindle winder is, in effect, old type No. 110 winder with stacking, buttress and tip-bunch devices added. It has also tip-cut and back-wind devices.

\section{TODO Universal Warp Tying Machine} K2 Type

Todo Seisakusho Ltd.

Todo's exhibits were both $\mathrm{K} 1$ and $\mathrm{K} 2$ types. Both types select yarn with a brush to avoid damage to the yarn. They can be used for filament yarns, too. They can be used for dyed-yarn fabrics and highdensity fabrics, because they leash new beam warp yarn together with leading old warp yarn However, a leashing machine is needed for leashing the new beam warp yarn separately. The hontters for $\mathrm{K}-1$ and $\mathrm{K}-2$ types are interchangeable.

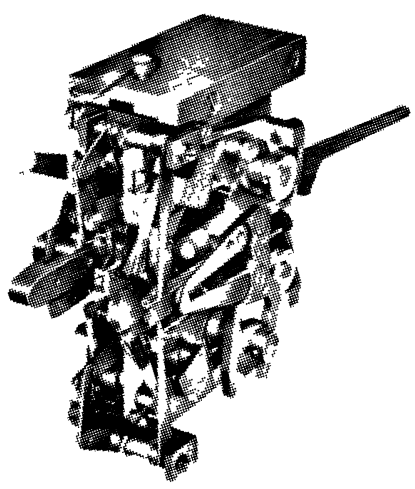

Fig. 26

TODO Universal Warp Tying Machine K2 Type

\section{Looms}

The only radically new exhibit was an uncom. pletely pilot loom entered by Enshu Ltd. The other looms on show had been exhibited elsewhere or were already on the market. There were no foreign exhibits, execept DSL, which is scheduled to be manufactured in Japan under technical tie-up. There were four looms made here under technical affiliations: (KOVO, UNIFIL, PAPA and PILOT).

Enlarged yarn beams and cloth rollers featured the mechanisms of most of the looms on view. There were spun fabric looms with 32 -inch yarn beams and 24 -inch cloth rollers. There were filament fabric looms with $600-\mathrm{mm}$ yarn beams and $400-\mathrm{mm}$ cloth rollers.

The filling-change mechanism of most looms included a photo-electric cell or an electric circuit as a yarn detector, with solenoid acting on the change mechanism. Electric methods, e.g., an electrical warp stop motion and a heater-using end-cutter, are looked upon as highly helpful to high speed operation. Japanese looms on display were equipped with excellent electric methods. (see Table).

HGR Type $4 \times 1$ Cop Change Automatic Loom

Hirano Loom Works, Ltd. 
The Filling Change motion has been changed from a mechnical to an electric system. The change signal, detected by the photo-electric feeler on the handle side, is tranmitted to the magazine side. Filling-change is ready when the magnet raises the ratch. This mechanism is featured by the fact that it dispenses with a memory device, detects the filling on the handleside and does filling-change on the magazine side. The mechanism makes it possible also to reduce the punch yarn length and to weave a two-filling pattern. A patent for the mechanism has been applied for.

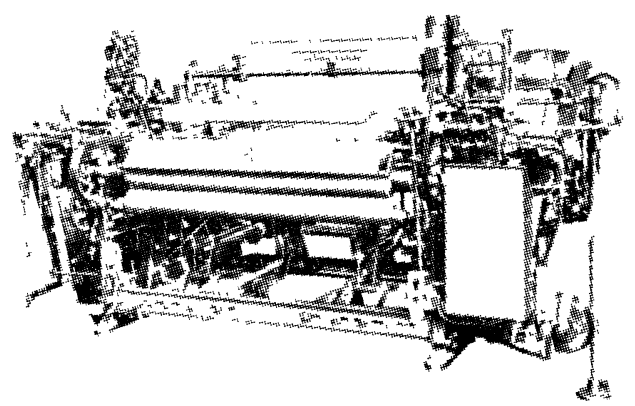

Fig. 27 HGR Type $4 \times 1$ Cop Change Automatic Loom

\section{(24) US Type Cop Change Automatic Loom}

\section{Tsudakoma Industrial Co, Ltd.}

The following features distinguish this loom from the other failament looms :

1) A cop change device is used to fit the loom for high speed operation.

2) Let-off device, taker-up and picker are assembled in each unit for easy replacement.

3) A modernized oiling system which reduces the frequency of oiling to once every 60 days for two-shift operations.

4) The yarn beam is enlarged in diameter from 510 to $600 \mathrm{~mm}$, the cloth roller from 340 to $400 \mathrm{~mm}$.

5) The parts subject to wear and tear are built of durable materials. For example, the stick is made of imported reinforced materials.

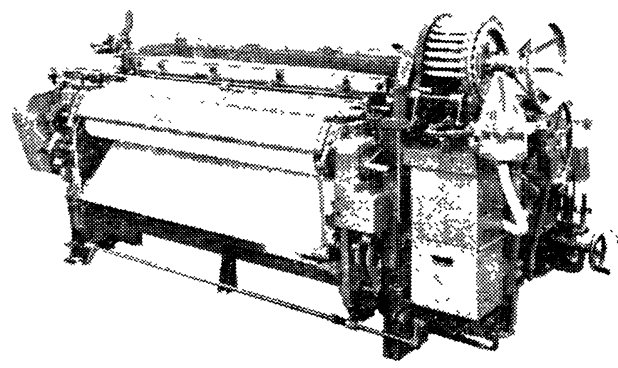

Fig. 28 US Type Cop Change Automatic Loom
These improvements preclude most conceivable fabric defects. This loom can be worked easily and works well.

\section{Jet Loom}

ENSHU, Ltd.

This loom is being built under a technical tie-up with KOVO ltd., with the following improvements credited to Enshu:

(1) A positive let off motion is used.

(2) A miss-pick-detecting device on the right-hand side and another on the left.

(3) A minimum selvedge-filling length of $1.5 \mathrm{~mm}$.

(4) Droppers designed to drop vertically to the loom.

This loom, long publicized as a loom for hydrophobic filament fabrics, lost its race for public appearance to Prince Jet Loom and made its bow at this fair. If its miss-pick detector works satisfactorily, it should reduce noise and increase productivity considerably.

\section{(26) KSL Type Cop Change Automatic Loom}

\section{ENSHU, Ltd.}

This loom differs in mechanism from Enshu's previous exhibit, in that it supplies filling with a Unifil, of which Leesona Corporation (U.S.) has reportedly sold 130, 000. This world-famous device is one which can be efficiently used in the stage between an automatic loom era and a shutleless loom era and is very valuable.

Looms are versatile in their uses, but shuttleless looms developed to date lack versatility. Unifil makes it possible to pick the filling directly from a cone or cheese by the usually dependable method, so that the versatility of the conventional looms can be retained. The conventional Japanese looms are being increased in speed and will soon pass the $200 \mathrm{rpm}$ mark. That will

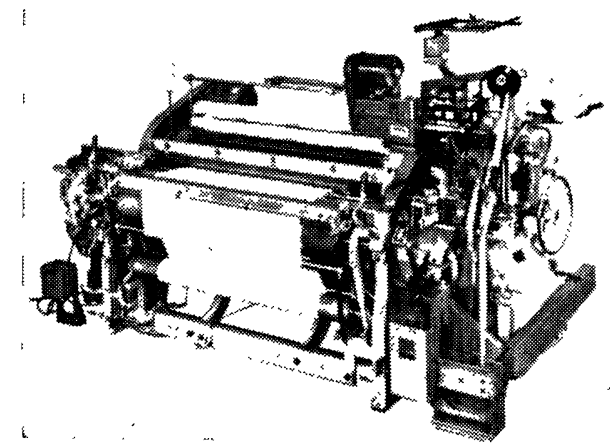

Fig. 29 KSL Type Cop Change Automatic Loom 
make shuttle looms nearly equal to shuttleless looms in serviceability for high speed operation. Unifil, which uses a shuttle for reliable picking, can stand up to shuttleless looms.

\section{(27) Pilot Loom}

\section{ENSHU Ltd.}

This loom is being developed by Enshu Ltd. under license bought from Dunham which has not yet complet. ed this device. Enshu is scheduled for completion in 1967. The repelling power of the spring coils placed, one each, in the shuttle boxes on the left and right let resin pilot $(105 \times 12 \times 13 \mathrm{~mm})$ fly to right and left. Yarns are drawn from cheeses on each side of the loom and picking is done. The pilot loom can be attached to a conventional loom by rebuilding the latter. The pilot is still in a testing stage. Meanwhile, it presents problems calling for solution. One is that it makes a louder noise than does a conventional loom.

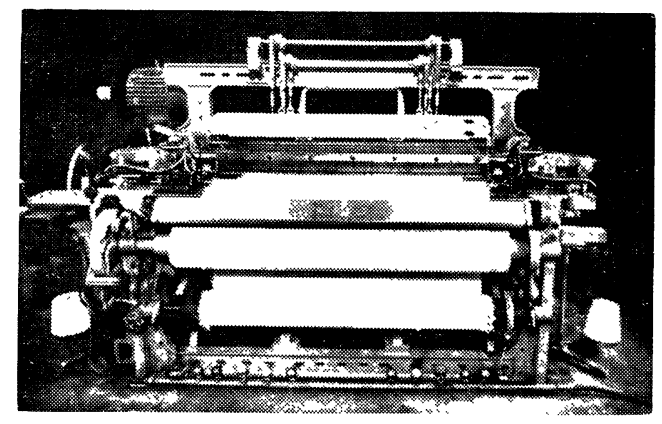

Fig. 30 a Pilot Loom

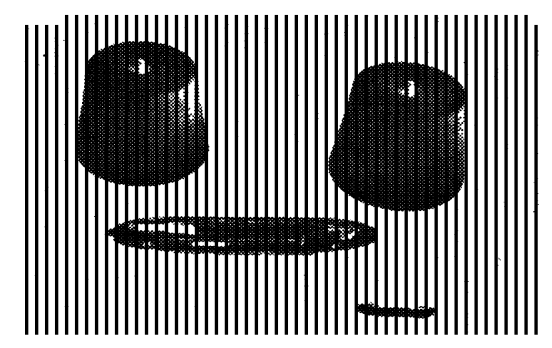

Fig $30 \mathrm{~b}$ Pilot of Pilot Loom

\section{HO Type Cop Change Automatic Loom}

\section{ENSHU, Ltd.}

This loom is distinguished from Enshu's previous exhibit by the fact that the tip bunch scratcher and the cop feeder have separate motion sources. The scratcher is an original idea. We believe Enshu's box loader can now be put into service.

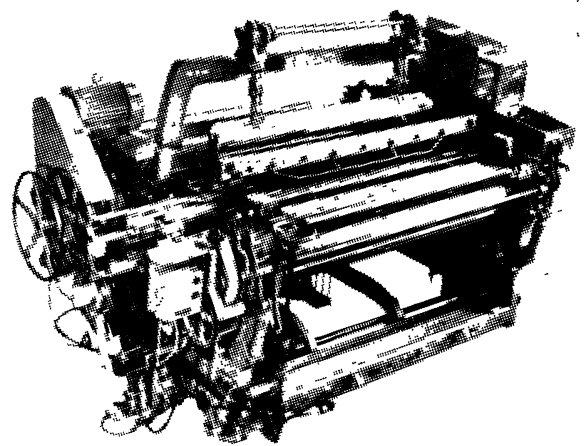

Fig. 31 HO Type Cop Change Automatic Loom

\section{(29) NZ 300 Type Cop Change Automatic Loom}

Howa Machinery, Ltd.

NZ 300 Type is an improvement on NZ 200 Type. It is equipped with a yarn breakage prevention device (and fixed picker), a large packaged roller (28 in. in yarn beam diameter and $24 \mathrm{in}$. in cloth roller diameter) and an accident prevention device (prevention of wrong change, etc.). The shuttle's narrow front face shortens the shedding distance. The small crank reduces eccentricity and breakage of warps. These improvements, however, go against high speed operation. The basic aim of this loom seems to reduce yarn breakage, dispense with operators or, at least, to reduce their number.

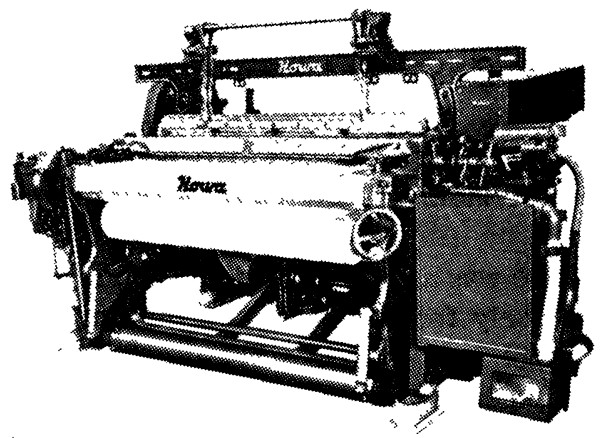

Fig. 32 NZ 300 Type Cop Change Automatic Loom

\section{(30) High Press Shuttle}

The Godo Shuttle Co., Ltd.

The speed-up of looms and production of highquality fibers demand strong shuttles which can stand high-speed operation and which can be maintained at small cost. This shuttle is made of a reinforced material by techniques imported from West Germany. Its durability and suitability for high speed operation fills 
the demand. Put on sale last July, the shuttle is about $70 \%$ higher in price than conventional shuttles.

\section{(31) Special steel-compound Mails}

\section{Godo Shuttle, Hirano and Miyawaki}

All these mails are interchangeable and do not produce yarn grooves easily. They can be mads-produced. The manufacturing methods are not published by the manufacturers.

\section{(Knitting and Braiding Machines)}

Knitting and braiding machines shown at the Japan International Trade Fair were very limited in number, undoubtedly because the event came only a month after the International Knitting Arts Exhibition (Tokyo) of March 8-12. Most of the exhibits had been entered in the Tokyo show.

Knit wear and braided articles make up such wide varieties and differ in their marketability. Almost all of them-except, perhaps, nets and ropes - are clothing materials and, therefore, subject to the vagaries of fashion.

What the end uses for knit wear and braided goods will be is, in many cases, known when their basic yarns are put on the knitting or braiding machine. Users appraise machines in their relation to the things which the machines make. To a user, a machine is a good machine if the thing it produces turns out to be good seller.

A cursory review of the Trade Fair exhibits of knitting and braiding machines leads one to make these comments :

1. There was a decrease in the number of machines produced merely for demonstration and an increase in the number of machines in service. The fact suggests a general tendency to look on the Trade Fair not as a mere show but as a medium of buying and selling, as an arena of competition for business.

2. There were a small number of machines which had undergone steady improvements and which had been regularly shown at the past fairs, too.

3. Circular machines, flat knitting machines and warp knitting machines "Made in Japan" on display were distinguished by eye-catching improvements in workmanship.

4. There were more machines "Made in Japan" on view than foreign units.

5. Generally, circular machines and stocking-mak- ing machines decreased in number. Flat knitting ma. chines were about the same in number as at previous fairs.

All these trends reflected well the latest situations in the knitting and braiding industries. The exhibits, therefore, made up a good showcase.

\section{(a) Circular machines}

\section{i) Jersey}

Last year marked the coming of the second stage in the development of jersey fabrics. It brought an end to the days when just any jersey fabric would do. The present is a stage of "re-examination," with the direction of future improvement suggesting itself.

A brief review of the history of jersey fabrics shows that they made their debut with only a limited market for them. Then a cycle of fashions started. The present is a stage of improvement with past experience as a guide.

The fabrics most popular for their structure are milanorib and pontiroma. This trend was clearly seen in the exhibits.

Only two kinds of double jersey machines were shown :

\section{Model ST-4 M-48 Jacquard Knitting Machine}

Okuma Machinery Works, Ltd.,

\section{Model ST-4 Moratronik Jacquard Knitting Machine}

\section{Okuma Machinery Works, Ltd.,}

These are products of the technical tie-up of Okuma and F. Morat (West-Germany). They have been entered on four occasions, on the first two by Morat alone.

Model Moratronik was shown at the fair for the first time, but had been previously introduced in this journal. Okuma seems to have fully mastered the workmanship in the short time since they entered into the tie-up with the German firm. The problem of the speed-change device for Model ST-4, we hear, has been solved by the Okuma system. The positive feeding system leaves room for improvement, because it is the 
same type as that for non-patterning machine, although ST-4 is a patterning machine. It may partly be due to the restriction of the tie-up.

Moratronik has an interesting feature: its Jacquard system is controlled by photocells. Users, however, should be good judges of patterned goods and good salesmen. Only one type of single Jersey machine was on view :

\section{(34) Model PFL Sinker Top Jacquard Terry Knitting Machine}

Fukuhara Precision Works, Ltd,

A good demand for single jersey fabrics has been expected for several years but it has yet to come. Major reasons are limited pattern variability and the difficulty of finishing and sewing because of the curl. ing of the selvage.

Raised jersey fabrics are expected to be in vogue this winter. Their exports are brisk. Model PFL has been produced as a raised jersey knitting machine with these facts in view.

PFL is an improvement on PLW Sinker Top Circular Knitting Machine. It has higher productivity than the usual loop machine and controls pile length easily.

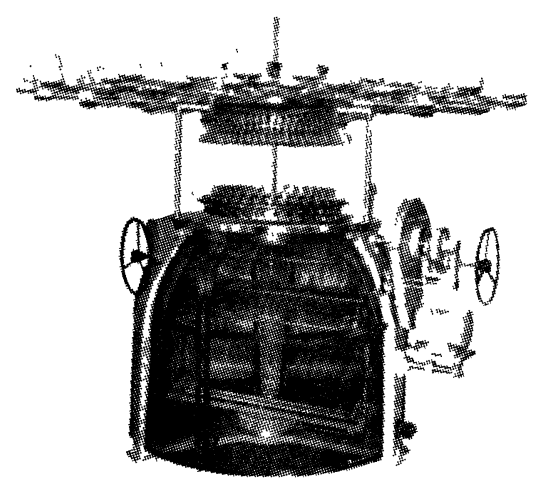

Fig. 33 Model PFL Sinker Top Jacquard Terry Knitting Machine

\section{ii) Underwear Knitting Machines}

Three types were on show:

\section{(35) Fukuhara High Speed Rib Knitting Machine Model JRB}

Fukuhara Precision Works, Ltd.

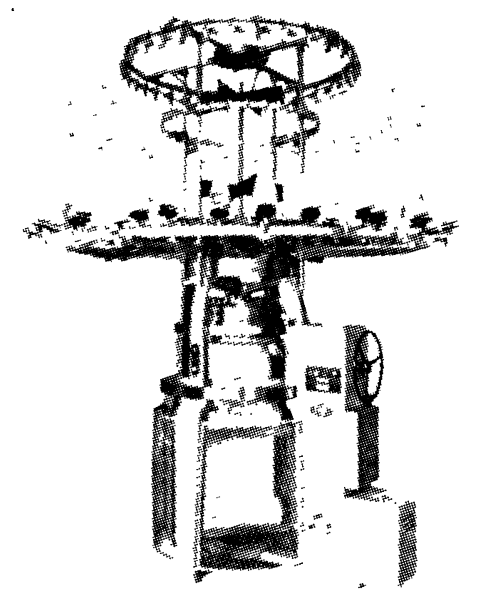

Fig. 34

High Speed Rib Knitting Machine Model JRB

(36) High Speed Circular Rib Knitting Machine Type CKTR

Tsugami Mfg. Co., Ltd.

(37) High Speed Circular Interlock Knitting Machine Type CKTL

Tsugami Mfg. Co., Ltd.

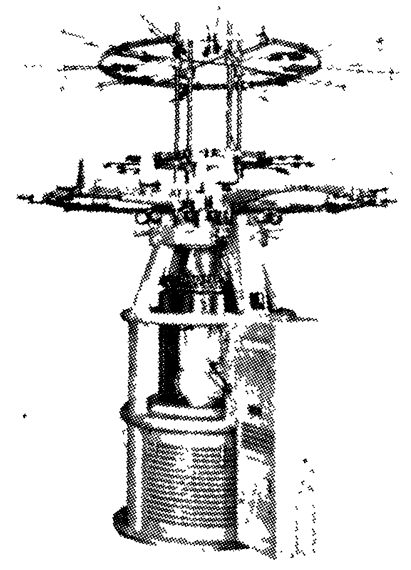

Fig. 35

High Speed Circular

Rib Knitting

Machine Type CKT-R

The underwear industry is said to be faced with a business depression. It has to overcome the depression by modernizing its process and improving the quality of its products. The key to accomplishing these tasks is to knit flawless fabrics at high speed.

Production flawless fabrics demands control of yarn tension or yarn length letout, detection of yarn defects 
before yarns are knit into loops, prevention of needle breakage and control of fabric take-up. To raise efficiency, it is necessary to increase the number of feeds and the running speed.

It is extremely difficult to decide whether the running speed or the number of feeds should be in creased for higher efficiency. The fewer the feeds, the less torsion for patterning and the better the mechanical property of fabrics. A higher speed can cause needles to be blown out by centrifugal force if the macine is of the cylinder revolving type or, if the machine is of another type, makes needles dance and results in an unevenly knit surface.

The relation between the stop device and the inertia of the machine should be carefully looked into because it has to do with these troubles.

In Model CKT-R, the emphasis is on, if anything, high speed. Model JRB has two ranges of feeders and leaves the choice to the user. Both models use positive feeding devices, JRB has the arrow system which won popularity for Model PIL-III produced by the same company.

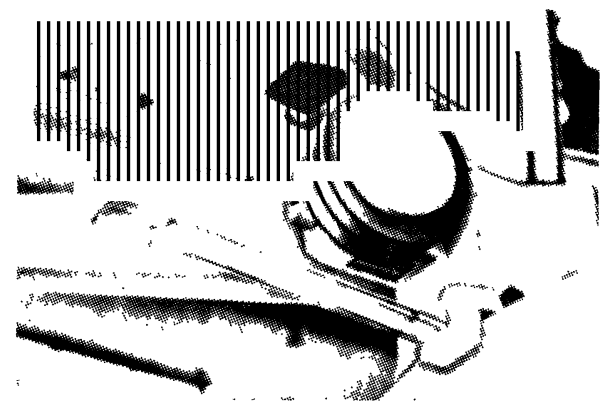

Fig. 36

Model CKT-R has the individually controllable, grooved roller system shown in Fig. 40. It uses alternately sinking cams and simultaneously sinking cams. Users and machine makers would be well-advised to get together and talk fully over the relation between the property of yarns used and the hand of knit goods.

\section{(b) Flat Knitting Machines}

Two machines drew notice:

Model PWM4, 4-color, Power-driven,

Semi-fashioned Garment Machine

Imon Machine Works.
(39)

\section{Model FF, V Bed, Full-fashioned \\ Garment Machine}

\section{Imon Machine Works.}

Since jersey fabrics made by circular knitting machines entered on a stage of over-production late in 1964, flat jersey knitting machines and auxiliary flat jersey knitting machines and auxiliary flat machines have come into increasing use. Flat machines are smaller in productivity than circular, but they have become a favorite because they produce a hard touch, a neat fabric surface and no distortion of pattern, and give wide range of structures to choose from.

Model PWM 4 is a fashioning device used chiefly for milano-rib. Model VFF is for full-fashioning in flat form. Both can be fitted to the ordinary flat knitting machines and are, therefore, best suited to the flat knitting machine industry in Japan.

\section{(c) Warp Knitting Machines}

\section{Model T-HWM L2-28 Warp Knitting Machine}

Tsugami Mfg. Co., Ltd.

Model YM-SCR-25-130 High Speed Lace Raschel Machine

Yamamoto Machinery Works, Co., Ltd.,

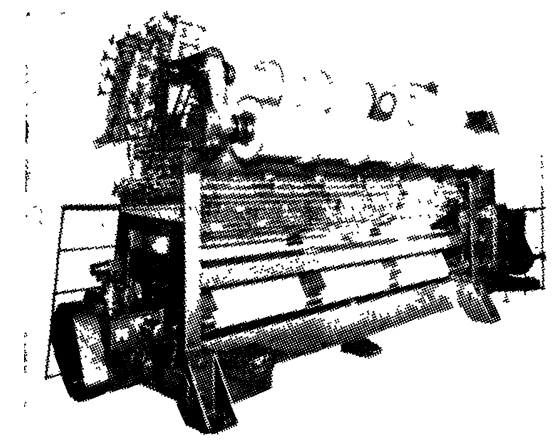

Fig. 37 Model YM-SCR-25-130 High Speed Lace Raschel Machine

Model TR-65 Lace Raschel Machine Takeda Kikai Mfg. Co., Ltd. 
Not many additional tricot knitting machines for filament yarns are being put in just now, but an increase in the tricot running speed is needed for modernization and high efficiency. The task is engaging keen study both here and abroad. The series of renovations made in T-HWM last year deserve high appreciation. The renovations have resulted in a smooth movement, less noise, fewer vibrations and stable running. Hardly any noticeable improvments have been made this year. The makers of T-HWM are urged to evolve radically new idea in preparation for the expected future boom in demand.

Raschel lace is a fashionable article which depends on design for popularity. It has formidable competitors in lace fabrics, including lever lace, which are much higher in quality.

Clearly, then, there is a need for Raschel knitting machines economical and yet capable of producing delicate designs which can face up to those produced by lever lace knitting machines.

\section{(d) Lace Machines}

\section{i) Quilting}

\section{(43) Speedy Model A Embroider Quilting Machine}

Kondo Sewing Machine Co., Ltd.

Changes in our way of life have opened up an increasing demand for quilting. In garments such as gowns, seams are not simply for stitching cotton and the basic fabric together. They go to make up a pattern. They are one of the decisive factors in the value of the garments. The machine introduced here produces lace patterns by sending the fabric back and forth as does a lace machine.

\section{ii) Embroidering}

\section{(44) Model H-8-D Unitec Automatic Embroidery Machine}

\section{Kotobuki Industry Co., Ltd.,}

Lacing, like quilting is expected to come into an increasing demand, but it has many problems because demand for it is influenced largely by fashions in women's clothing. (e) Accesories to Knitting Machines

\section{(45) Circular Cleaner}

Ohara Iron Works, Ltd.

Knitting of spun often breaks yarns, and needles, mixes neps and makes small holes because fly comes in, especially when cotton yarn is being knit into underwear. In some cases, fly-caused defects amount to one third of total number of defects in a fabric.

The fly preventive method used in many factories is to clean the machines periodically with electric cleaners, but its efficacy is inadequate.

The device introduced here, a cleaner for circular knitting machines, sweeps fly from yarn-guides, tension devices and the cylinder part with compressed air from nozzles, and sends fly into a duct in the center of the machine or drops it to the floor. It deserves notice as a help in the modernization of the process and in production of high-quality fabrics.

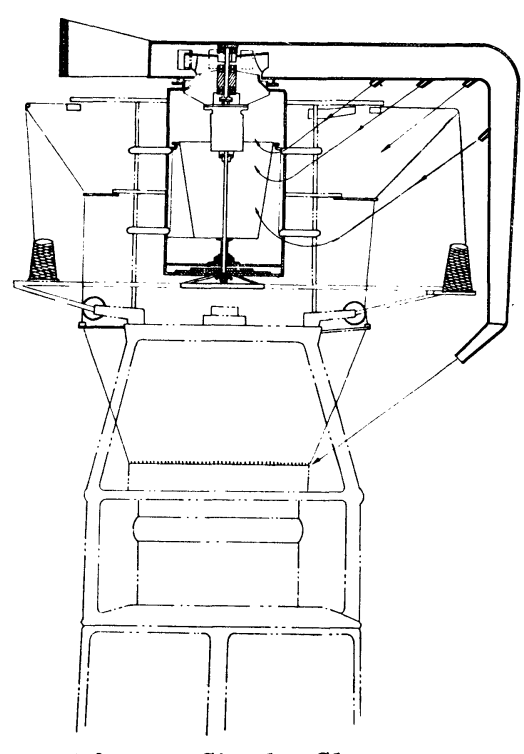

Fig. 38 Circular Cleaner

\section{Dyeing and Finishing}

Numerous kinds of synthetic fibers have been developed year after year in the last 30 years. Fabrics and knit wear made of excellent blends of natural and 